\title{
Article
}

\section{Space, relations, and the learning of science}

\author{
Wolff-Michael Roth ${ }^{1} \cdot$ Pei-Ling Hsu ${ }^{2}$
}

\begin{abstract}
In the literature on the situated and distributed nature of cognition, the coordination of spatial organization and the structure of human practices and relations is accepted as a fact. To date, science educators have yet to build on such research. Drawing on an ethnographic study of high school students during an internship in a scientific research laboratory, which we understand as a "perspicuous setting" and a "smart setting," in which otherwise invisible dimensions of human practices become evident, we analyze the relationship between spatial configurations of the setting and the nature and temporal organization of knowing and learning in science. Our analyses show that spatial aspects of the laboratory projectively organize how participants act and can serve as resources to help the novices to participate in difficult and unfamiliar tasks. First, existing spatial relations projectively organize the language involving interns and lab members. In particular, spatial relations projectively organize where and when pedagogical language should happen; and there are specific discursive mechanisms that produce cohesion in language across different places in the laboratory. Second, the spatial arrangements projectively organize the temporal dimensions of action. These findings allow science educators to think explicitly about organizing "smart contexts" that help learners participate in and learn complex scientific laboratory practices.
\end{abstract}

Keywords: scientific laboratory practices, field, learning spaces, ethnography, distributed cognition

The focus of this study, space and the learning of science, emerged while we were members of a nationally funded research center the mission of which was to conduct investigations into "authentic science experiences," "scientific research apprenticeships," and "authentic practical inquiry." The center also had as its mission to provide students with real science experiences, some of which were related to scientific laboratories whereas others were oriented towards science and the environment. As part of our contributions to the center, we were interested in laboratory experiences, because these are among those settings that allow students to develop a sense of the nature of science (e.g., Roth 1995a). The center was funded, among others, for its proposal to provide internships in operating scientific laboratories because of their potential where students may become interested in science careers. There are in fact "urgent calls" for

\footnotetext{
${ }^{1}$ W.-M. Roth

MacLaurin Building, University of Victoria, Victoria, BC, V8W 3N4, Canada

Email: mroth@uvic.ca

${ }^{2}$ P.-L. Hsu

Department of Teacher Education, College of Education, University of Texas at El Paso, El Paso, 79968, TX, USA
} 
academic scientists "to engage with $\mathrm{K}-12$ science improvement efforts in myriad ways, including outreach and internship programs for high school students" (Cacciatore 2011, p. 248). One of the key findings emerging from our data analyses was that the material-spatial organization - either as it existed or as specially prepared - is related to the rapidly changing forms of participation observed. This is an interesting result, because it suggests that noncognitive, non-conceptual aspects of the setting, such as its spatial organization, foster the development of competencies in scientific laboratory practices. Such relationships between space and conceptual learning have shown to exist in open inquiry science classrooms (Roth 1996) and during practicum settings where new science teachers teach together with more experienced regular teachers (Roth et al. 2005). Although science educators have been interested in the kinds of learning that laboratory activities tend to support and although they recognize that there may be an influence "by the materials, apparatus, resources, and physical setting," they also maintain that these are of lesser importance in the face of climate and expectations, collaboration and social interactions (Hofstein and Lunetta 2004, p. 35). Moreover, a description of the state of the art and recommendations for research topics on science laboratories does not include the spatial organization of activities (Hofstein and Mamlok-Naaman 2007). It therefore comes as little surprise that there currently exists very little work in science education about how the spatial organization or the laboratory materials might enable conceptual learning, where we understand learning to be "discernable by noticing our and others' changing participation in changing social practices" (Roth and Barton 2004, p. 153).

This ethnographic study was designed to investigate how the physical-material aspects of a field - a materially and socially structured space such as a scientific laboratory, with its specific interests, relations of power, rules, forms of language, and material configurations (Bourdieu 1980) - enable the changing participation of high school students. The internship, an interest to science educators in its own right, serves in this study as a specific context that particularly well reveals the phenomena we report. The fact that the high school students we followed through their internships were unfamiliar with the field provided us with an opportunity to study the role of space and spatial relations when someone is new to a setting. In such situations, normally invisible aspects of work are made explicit in the interactions between regulars and interns. This is why Garfinkel (2002) calls such situations, also drawing on the perceptual metaphor, "perspicuous settings." This term "collects the policies and methods of [ethnomethodological] research for an actual, in vivo occasion of inquiry" (p. 181). The term tends to be explained "by saying that Ethnomethodological studies are 'embedded' in a local culture . . . and under that condition the analyst examines various objects in that culture" (p. 181). The questions that organize the present investigation include "What are the relations between (a) the spatial organization of a laboratory and (b) the language between its normal inhabitants and the interns that instruct the former?" and "What are the relations between the spatial organization of the laboratory and the sequencing of interns' actions?" Answers to these questions may assist science educators in designing laboratory settings as smart spaces, which, in the very way that they are designed, enable changing participation (i.e., learning). This is consistent with the call for creating "opportunities to participate in ways that emphasize students' strengths and address their interests ... [r] ather than setting up situations that bring out disability or inability" (Roth and Barton 2004, p. 154, emphasis added). Much as well-designed appliances and artifacts decrease complaints about usability, school laboratory environments designed as smart spaces, in which the configuration of spaces and placement of artifacts projectively organize students' actions, might be able to lessen their complaints about not knowing what to do and how to do it. Here we understand the adjective "projective" as a cognate to "affordance" such that particular 
actions consistent with a spatial organization are more likely to occur in the future than other possible actions. Thus, if there are two equivalent artifacts, the one located closer is more likely to be used than the one further away; if there are two artifacts to be used in future actions, as shown in this study, novices are more likely to reach for the one closer to them and use it rather than the one that a competent practitioner draws on next. Or, to provide an everyday example, users of a kitchen stove are more likely using the correct dial if the dial arrangement reflects the arrangement of the heating plate (e.g., in square or rectangular arrangement rather than linear, as found with many stoves).

\section{Learning spaces}

The latter part of the 20th century has seen a shift in learning theories from information processing, concerned with the manipulation of symbolic systems, to situated and distributed cognition, concerned with how the entire unit of humans-acting-in-physical-settings produce relevant cognition (e.g., Hutchins 1995a; Henriqson et al. 2011). Research now suggests that the capacities for problem solving differ with change of context and that the structure of a setting may support or interfere with knowing and learning. In fact, such research suggests - consistent with cultural-historical and cultural-sociological approaches to human practices - that the individual is not the appropriate unit of analysis: The setting as a whole, including its material, social, and ideal aspects constitutes the appropriate sense-giving unit. For example, it is difficult to understand why individuals, who have no problems in solving arithmetic tasks while walking through the aisles of a supermarket, should have trouble solving equivalent problems in paperand-pencil format (Lave 1988) if mental structures are all there is to cognition. Such mental structures (conceptions, frameworks) should be transferrable to another place, where people could enact them. The fact that they do not do so is used by Lave, as by other scholars, to suggest situated models of knowing and learning. Some science educators, therefore, have suggested choosing alternative minimal units of knowing and learning such as "Davie-in-the-mathematicsclass-required-to-do-data-analysis or Davie-in-another-seventh-grade-class-as-teacherscaffolding-inquiry-in-and-about-the-creek" (Roth and Barton 2004, p. 150-151). It is only within such holistic units - which include the object/motive of activity (inquiry), the societal relations (Davie as teacher of other students), and the physical setting (in and about a creek) that we can understand changing participation. As these authors point out, science "educators must focus on enabling changing participation, that is, enabling new forms of collective activity" (p. 153). The creation of environments that support rather than hinder people in exhibiting competencies and learning requires us to know more about how patterns of participation interact with the spatial organization of the places in which they are to work and learn.

There are features of settings that projectively organize how people act and solve problems. First, language is indexical: it directly refers to the physical setting and cannot be understood without it. Indexical terms - such as here, there, this, that, now, and next - are pervasive in mundane language e.g., Goodwin, 1986). These indexical terms are context-dependent and only exhibit their sense in the context where they appear and of which they are a part. These terms, though seemingly unrelated to conceptual content, actually contribute to the intelligibility of conversations because they bring the physical context and its spatial relations into the practice as an important resource for understanding. Cognition no longer is lodged in the head but arises from the physical-material, social, and conceptual-ideal organization of the field as a whole. This then allows cognitive scientists to ask questions that to many may initially sound strange: "How does a cockpit remember its speed?" (Hutchins 1995b) or "How does a cockpit calculate its speed?" (Henriqson et al. 2011). That is, the focus no longer is on how the pilot remembers 
something that is in his/her mind but how something is remembered or calculated in and by the cockpit. Other researchers suggest that not only the classical indexical terms and pointing gestures have indexical function but all language, every word, has indexical function (Garfinkel 1967). As a result, knowing a language is indistinguishable from knowing one's way around the world more generally (Rorty 1989): Every word of a language has its corresponding places in the everyday world, and every situation of the everyday world is characterized by specific forms of language. For this reason, some educators shift from speaking about "smart people" to speaking about "smart contexts" (Barab and Plucker 2002). Thus, in the present study, the knowing and learning we observe is a function of people-in-context rather than of the interns in and of themselves. Paraphrasing Hutchins we might ask, "How does a science lab filled with newcomers know and learn?"

Second, when settings are analyzed as irreducible wholes, we may observe relationships between material artifacts and human actions, each of which are parts that can be understood only in their relation to the whole and to all other parts. Rather than mental calculations, we may observe dieters using a knife dividing into sections a full cup of cottage cheese dumped on the table to yield the amount required for an adaptation of a recipe (e.g., Lave et al. 1984). The structure of mathematical practices in a dairy factory was related to the spatial arrangements of products in boxes and on crates (Scribner 1984). Speed card booklets, runway analysis charts, flight management computers, and laptops are irreducible moments of the cockpit that helps it calculate and remember the speed of the aircraft (Hutchins 1995b; Henriqson et al. 2011). Such findings illustrate how artifacts-in-use structure practice and learning. In fact, material artifactsin-use, spatial configurations of the setting, and human practices are irreducibly intertwined so that we cannot understand one without the others. Whereas such studies provide ample evidence about the situated nature of knowing and learning, spread across people, artifacts, and their constellations, science educators - in classroom tests and examinations, clinical interviews, or international assessments - still attempt to assess knowledge as something that exists independent of context and the particulars of the language used therein (e.g., Roth 2008).

Third, social interactions and division of labor shape the ways in which individuals act and solve problems and even shape perceptions normally theorized as purely psychological processes (Hutchins 1995a). Thus, the linguistic, material, social, and cultural resources - e.g., words, gestures, gazes, body positioning, body movements, and artifacts - all are part of the rich ecology of material sign systems that structure actions and interactions.

When the setting as a whole is the minimum sense-making unit, performance is understood as property of the joint but distributed cognitive system. This has led researchers to rethink many common-sense notions. For instance, concepts such as plans, traditionally deemed to be entities in people's mind to explain and determine people's actions, are now understood as projective and retrospective accounts of actions (Suchman 1987). As such, plans are resources for situated actions located in the context of practical activity rather than causes of actions. That is, "the coherence of action is not adequately explained by either preconceived cognitive schema or institutionalized social norm" but is "an emergent property of moment-by-moment interactions between actors, and between actions and the environment" (p. 179). In all studies reviewed here, the individual-acting-in-setting is the minimal analytic unit. Speculations about what is in the individual mind independent of action and setting do not help understanding events and practices. In different sociological theories this situation is reflected in the form of agency-structure dialectics or the homology of cultural practices-generating habitus (i.e., systems of structured dispositions that structure perception and action) and (social, material, cultural) field. The upshot of this position is that we comprehend (i.e., understand) the world because the world 
comprehends (i.e., includes) us.

Anthropological studies suggest a "quasi-perfect coincidence between habitus and habitat, between the schemes of the mythic vision of the world and the structure of domestic space" (Bourdieu 1997, p. 176). Here, the habitat is all encompassing, material and social; and our human dispositions, the habitus, is adapted to and evolves in correspondence with this habitat. A similar coincidence has been observed between the material-temporal organization of classrooms and the hierarchical nature of social structure (e.g., Foucault 1975). The material-temporal organization imposes a physical discipline that shapes the mental discipline. But this coincidence does not exist when someone moves into an unfamiliar cultural field (newcomers notoriously act inappropriately). One ethnographic study among ecologists describes the emergence of disciplinary thinking practices from the physical discipline imposed during apprenticeship as honors thesis and Master's degree ecology students undergo the hardships of field work (Roth and Bowen 2001). The authors conclude that disciplinary, disciplined minds emerge with and from disciplined bodies. Another study exhibits an increasing coincidence between discipline specific (mental) dispositions and physical structures of the field (boxing ring) when a sociologist became a boxer to study boxing (Wacquant 2004). Such investigations suggest that the very physical-material organization of a "habitat" and the observable material practices therein anticipate - i.e., enable and, in fact, projectively organize - the changing participation of newcomers until their practices exhibit the same "quasi-perfect coincidence between habitus and habitat" that characterizes the residents of the field. We use the notion of projective organization to express the relation between spatial organization and structures of practical actions that is of the same kind as the relation between plans or instructions and situated actions: The former orient participants but do not determine (cause) what they do, "because there is no way of prespecifying the conditions under which [the significance of an instruction] is going to intrude upon your local island of order" (Garfinkel 2002, p. 205, emphasis added).

Informed by studies of cognition in setting and the situated nature of learning, educators also began to redefine theoretical concepts that take into account the role of context in learning. For example, ability and talent - traditionally defined as properties of individuals - now are redefined as "a set of functional relations distributed across person and context, and through which the person-in-situation appears knowledgeably skillful" (Barab and Plucker 2002, p. 174). Despite these and similar investigations, little research actually has been conducted concerning the relationship of space and changing forms of participation and activity in science. One exception is a study that investigated how the physical arrangements of students around a single computer not only structured the learning space but also mediated what physics content students were learning from the modeling software they were using and how they were learning (Roth et al. 1996). Another exception is a study of science learning in a design environment (Roth et al. 1999). It found that different artifacts, social configurations, and physical arrangements were associated with structurally different forms of participation in a sixth-/seventh-grade science course. For example, those individuals in physical proximity to the focal artifacts have had greater opportunities than those who sat out of reach to engage in and thereby dominate the content and structure of conversations. Changing seating arrangements such that heretofore silent (excluded?) students came within physical reach of the focal artifacts increased their contributions to discussions, while simultaneous movement of frequent contributors to the back of the classroom decreased their dominating influences. That is, that study exhibits important relations between (a) material artifacts and physical organization and (b) content and form of classroom language. However, the study left unanswered questions about how a language changes and how action sequences might be enabled by different spatial organizations of the 
setting. Answers to such questions are important because they provide science educators with information about how they might realize Barab and Plucker's call for creating smart contexts where they would observe much more competent and changing forms of participation than they currently do. In the present study, therefore, we investigate the relations between spatial configurations and changing forms of participation and the temporality of actions. An internship experience for 11th-grade high school students in a scientific laboratory serves us as a perspicuous setting in which such relations become particularly visible and salient.

The importance of the present study arises from the fact that it was designed to seek an understanding of the relationship between the material organization of a cultural field and the cultural practices that exist and emerge within them. On the negative side, the material organization might contribute to inequities and societal stratification (e.g., Roth et al. 1996), whereas on the positive side, the material organization may facilitate newcomers in developing what they perceive to be desirable practices. In fact, several high school students participating in our internship no longer envisioned themselves in a science-related career following what they perceived to be the repetitive routine and drab of a scientific laboratory.

\section{Research context}

This study was designed to study several questions concerned with the manner in which the spatial organization of a university science laboratory (i.e., the field) supported the participation of high school students in scientific laboratory practices. The internship was organized by a nationally funded center in which natural scientists, science educators, and faculty from other departments (e.g., educational psychology, geography, environmental science) collaborated on general scientific literacy and on the recruitment and preparation of future scientists. From the perspective of the residents in the scientific laboratory, the purpose of the internship was to enable high school students' participation in (a) the regular day-to-day work of a scientific laboratory, (b) the application of scientific knowledge to daily life, and (c) the activities of a real science laboratory. The science educators in the center were interested in studying changing forms of participation that occurred as high school students moved from the school to the science laboratories and back into the high school setting. This paper focuses on the internship only because of its potential as a perspicuous setting.

\section{The scientific laboratory and its "inhabitants"}

To understand the normal everyday functioning of the laboratory, details of their work, and the mundane - everyday, ordinary, and therefore not worthy to mention - practices members enact, we began our investigation by conducting a six-month ethnographic study of the 40+member university science laboratory that is one of the world-leading facilities for the analysis of water quality. This ethnographic study allowed us to understand, as shown below, that some of the actions in the laboratory changed when the students were present. During this period, which preceded the internship, we observed and videotaped the laboratory work and the weekly meetings of the research group. The laboratory members included a chief scientist of the research program (a co-PI on the center grant), a laboratory manager, three scientists, five postdoctoral fellows, one administrative assistant, 13 technicians (field managers, research assistants etc.), 15 graduate students, and a variable number of undergraduate co-op students.

The chief scientist and the laboratory manager (scientist) took full responsibility for organizing and supervising the internship, which directly involved the high school students and five laboratory technicians (two technicians shared one group of high school students). The five technicians were in their 20 s or 30 s and had biology-related majors; they had recently graduated, 
had no pedagogical training, and never had trained novices before. The technicians designed internship plans for their groups based on the goal of integrating students to the maximum extent possible so that they would get the feel of real, everyday laboratory work; the technicians discussed the feasibility of their plans with the scientists. The technicians usually worked in the laboratory for eight hours a day and sometimes went into the field to collect samples; working on different projects within the laboratory, they cooperated with graduate students while being supervised by the scientist responsible for the particular project. The technicians went back and forth in the laboratory to use different equipment and instruments for their work, or, if necessary, went to other laboratories to access and use instruments. From these aspects of their work, the chief scientist and laboratory manager selected those laboratory assistants that they deemed most suitable for introducing the high school students to scientific research work.

\section{Internship participants and their work}

Thirteen ( 2 male, 11 female) eleventh-grade students simultaneously enrolled in a biologyand in a career-preparation course participated; four groups of three or four students were videotaped during the internship. A first meeting was organized for the students, scientists, and technicians to discuss the science projects, negotiate time schedules, and discuss the work in preparation for the internship. The 13 students worked with their technician assigned to four ongoing scientific projects spending, depending on group, 4 or 5 days over two months for a total of between 10 and 16 hours in the laboratory. Groups I-IV focused, respectively, on (a) tracking bacterial sources in surface waters (the exemplary group in the present article); (b) tracking chemicals in aboriginal seafood; (c) determining pharmaceuticals products in municipal wastewater; and (d) designing household bio-sand water filters.

Each of the four ongoing projects required different scientific knowledge, techniques, and use of technology and equipment. The technicians made all necessary arrangements for the work to be conducted by the high school students in their respective groups. The high school students started their internship by reading relevant scientific papers that the technicians selected. They participated in discussions and scientific seminars, and practiced particular techniques in science projects in laboratories or collected samples from the field. At the end of the internship, the high school students presented their work and experiences to an audience of about 50 individuals including laboratory members (scientists, technicians, and university students), their biology teacher, other high school students, and staff from the center for scientific literacy. The regular members of the laboratory were amazed by the tremendous level of competence that the high school students had developed in the course of their presence.

\section{Data sources}

This paper focuses on a particular aspect of the larger study we conducted: the association between the material aspects of the field (scientific laboratory) and the changing forms of participation observable therein. To capture the details of participants' practice in the laboratory, we followed similarly oriented studies investigating the relationship between spatial organization and participation (e.g., Goodwin 2003a) and used video camcorders to record the four groups in the course of their apprenticeship in the scientific laboratory. Thus, in addition to our ethnographic records, a total of about 50 hours of video footage (similar in amount from each group), became the focus of our analysis and constituted the sources for the data that we mobilize as empirical evidence supporting and exemplifying our findings. In this way, almost all of the time that the four groups spent in the laboratory was recorded. To transcribe videos, we adopted an existing notation system (see Appendix). In this study, we draw our examples from 
the internship of one group led by the laboratory technician Nora, who worked on the identification of fecal contamination (i.e., E. coli) of surface water. This selection has been influenced by the fact that we obtained full permission from all participants in this group to use their photographs.

\section{Analytic stance and research policy}

To investigate the relation between the spatial organization of a laboratory setting and language game or practice, we found it useful to follow the precepts of ethnomethodology, which intends to explicate the nature of everyday work practices (Garfinkel and Sacks 1986). We heeded the ethnomethodological recommendations not to confuse and conflate the practices in which high school students participate and those that are characteristic of science. We understand the internship and all interactions surrounding it as a social phenomenon sui generis [of its own kind] that needs to be treated as such (Durkheim 1919). We are scholars interested in the science-related practices in different settings (high schools, science laboratories). We draw on those methods most appropriate and dialectically related to the chosen research object. Here, this research object focuses on the relationship between the material organization of a field (scientific laboratory) and the changing forms of participation in the practices observable in this field. Given that we are interested in the formal structures of practical action, some ethnomethodological studies constituted an appropriate starting point for our research project.

The nature of practices becomes especially salient when things that normally work no longer do. In these situations, members to a setting exhibit to each other, and thereby to the analysts as well, how the structural properties of practical action as produced and recognized by insiders. Mundane language, intonations, gestures, body positions, and body movements are some of the resources for making salient situationally relevant issues. That is, we "use the ways members have of making clear to each other and to themselves what is going on to locate to our own satisfaction an account of what it is that they are doing with each other" (McDermott et al. 1978, p. 247). This approach, designed to produce an ethnographically adequate account of the events, provides a member's view of practice in the making. The patterns we identify and report on are general in the sense that they are produced by members to the setting for members to the setting - the students, in copying Nora's squatting position (see below) make available to the observer that they noticed the squatting. Thus, every culturally competent individual not only understands the patterns but can actually contribute to producing them.

For the purpose of the analysis, we take the recordings and transcripts as natural protocols of the internship in the making. Any single episode may be used to reveal the mundane methods people (ethno-) use to exhibit relevant structure of their lifeworld for each other. That is, we understand the participants in the internship experience to have made available to each other everything required to allow the rational, accountable nature of their practice become observable in the setting. This means that the competent analyst has to bring those same "vulgar endogenous competence" "of what comes "naturally" (Garfinkel 2007, p. 15, 45). This leads us to the following research policy: "You must be competent with respect to the practices that you are examining if there is to be any chance at all that you could come up with the cogent, inspectably, instructably reproducible phenomena that witnessing consists of' (Garfinkel 2002, p. 212). The extensive time spent in the laboratory prior to the study, and our training as research scientists and teachers, allowed us to understand conversations between the laboratory residents and the visiting students. 
To describe, articulate, and theorize the orderly properties observable in the field of our interest, we studied the data sources independently and collectively. Our joint analyses are modeled on Interaction Analysis (Jordan and Henderson 1995). Here, the analysts interact with each other to study the interactions shown on video. Analysts thereby come to be accountable to each other for their observations: they cannot just interpret events as they want but are required to provide evidence visible to them in the same way that it is to the individuals in the recorded events. This approach to working forces us to think like, and use the methods of, those whose practices we study. We stop the recording when someone identifies something of interest. We describe the event that caught our attention and analyze and replay it as often and as long as required until a collective sense emerges that everything has been said. We then continue playing the tape until another aspect catches our attention. These meetings are recorded so that we can subsequently produce our analyses based on what was said during the session. When we analyze videotapes individually, we immediately transcribe and annotate our materials while moving through a tape in a frame-by-frame fashion, clipping screen images of "interesting" moments and pasting them into an open document of our word processor. We then construct a description of the event and add analytical comments.

The descriptions, theories, and concepts developed during individual and joint analysis sessions are then used to look for similar instances in the data sources. As a result, we know that there are many comparable episodes that illustrate the same phenomenon. As a matter of principle, we select episodes that depict a phenomenon sufficiently clearly for those unfamiliar with the tapes; or we may select examples only from one group of participants, because this gives our readers a sense of inner coherence in the development of the participants.

We analyze the recordings consistent with (a) speech act theory and conversation analysis and (b) a sociological orientation to linguistics where a conversation is taken to be an irreducible social phenomenon. Each pair of consecutive turns is the minimum unit that makes sense, where a turn may exist entirely in the form of pointing or a changing body orientation. Thus, we do not say or write that someone "has asked a question" unless a participant in the setting has treated an articulation as such, which is apparent from his/her turn; we do not write about the effect of a pointing act unless someone else in the setting provides evidence to responded to the act as a pointing gesture. We are not concerned with the different "meanings" someone might have in her head. Rather, we only allow into our analysis what participants objectively make available to each other and, therefore, also to the analysts. In our joint meetings, therefore, we hold each other to account for our claims that need to be substantiated by evidence clearly visible to all participants in the analysis meetings. For example, the following turn pair is from Episode 2a:

$11 \mathrm{~N}$ : “UM "UM youre seeing the connection?

12 C: ya=i see the connection;

From an analytic perspective, to understand what is going on from an insider (the member's) perspective, this is an irreducible question-answer pair. Turn 11 is a question only because Turn 12 is a called-for answer; and Turn 12 is an answer only because Turn 11 is the question calling for it. That is, "question" and "answer" are manifestations of a higher-order unit: (a) the turn pair from the conversation analytic perspective and (b) an utterance with its social evaluation from the sociological approach to linguistics. This unit cannot be reduced to either speaker. This approach therefore allows us to understand the internal dynamic of an episode as an unfolding event. The question mark at the end of Turn 11 only indicates that the intonation rises towards the end of the locution, and the semicolon at the end of Turn 12 marks a decrease in the intonation in the direction of the end of the locution. A rising intonation tends to be heard as a 
question even when the grammatical structure is not consistent with a question; and, Turn 12 is evidence that such hearing has occurred. It begins with an affirmative "ya," and is followed by an affirmative (falling intonation) quotation of the preceding speaker.

\section{Spatial relations projectively organizes language and action sequences}

This study was designed to investigate the relationship between the spatial structures of a field and changing forms of participation (i.e., teaching and learning). An internship in a scientific laboratory served us as a perspicuous setting where normally invisible aspects of the mundane practice become visible. Specifically we asked: "What are the relations between (a) the spatial organization of a laboratory and (b) the language between its normal inhabitants and the interns that instruct the former?" and "What are the relations between the spatial organization of the laboratory and the sequencing of interns' actions?" In the following sections, we articulate our findings along the two dimensions opened up by our research questions. First, we show how existing spatial relations of the field tend to project future organizations of the language involving interns and laboratory members. In particular, spatial relations and workflow requirements projectively organize where and when pedagogical language might happen; and there are certain mechanisms that connect the languages that differ across the different spaces in the laboratory. Second, we exemplify and analyze how the spatial organization of the field is related to the temporal organization of action sequences.

\section{Spatial relations projectively organize language}

Many present-day theories of cognition tend to take knowing as something people construct in their minds and which they do or should be able to deploy independent of the particulars of the field in which they participate. Even those studies taking sociocultural and sociological perspectives tend to ask what scientific knowledge or science identity students construct rather than asking questions about ways of being or participating. The very idea of the school as a place for learning scientific knowledge that subsequently can be applied out-of and after school embodies a particular epistemology, which is premised on the idea of knowledge in the head and independent of the field. Whereas situated approaches recognize cognition to be situated in and distributed across the setting, there is little science education research to show why the physical organization of the field and knowing/learning science might be irreducibly intertwined (but see Roth and McGinn, 1998, for how the "military-like seating arrangements" and the presence of "invigilators" are part of the construction of "A students" and science dropouts). To exhibit the relations we observed, we begin by focusing on how the spatial structure of the field organizes in advance - in anticipation of and thereby projecting into the future - the technicians' instructions for guiding the actions of the high school student interns. We then show how the technicians' own actions are reconfigured in turn by the changes arising from the physical presence of others. That is, the spatial structure of the cultural field not only projectively organizes the actions of the interns but also those of the laboratory regulars. Interns therefore no longer participate in science "as it really is" (i.e., as we observed it when the high school students were not present) but participate in a new form of activity that includes them. In this study, we investigate this new form of activity in its own right. Thus, for example, students do not participate in speaking laboratory talk that would occur in their absence; rather, they participate in speaking forms of talk typical of the internship situation. Our episodes exemplify the close relationship between spatial structure and the nature of the laboratory instructions provided. To illustrate how space projectively organizes the internship instruction, we first provide an ethnographic description of the layout of the laboratory. Next, we show how spatial structure projectively organizes the 
internship language and how different structures shape the (changing) participation. Finally, we discuss how characteristics of material artifacts and tasks projectively organize the conversations related to student actions. For the purpose of this paper, we draw our examples from one group to provide a sense of coherence and continuity rather than proliferating the number of actors featuring in the paper. We make reference, where appropriate, to the same kind of findings in other groups.

The laboratory layout and pedagogical spaces During the internship only certain physical locations in the laboratory were explicit pedagogical spaces - spaces that harbor pedagogyrelated artifacts, and activities for instruction. The location of these spaces and the activities occurring therein arose from the workflow associated with the particular experiment that a group conducted. That is, although the laboratory is spacious, only certain locations associated with the workflow were utilized as part of the natural, indigenous pedagogical practices of the technicians in teaching and guiding the interns. For example, in the case of Group I only four physical locations were used for instructing the high school students. The laboratory includes five rooms: (a) a staff office where lab members worked with computers and paper work; (b) a head office where the lead scientist worked and organized small-group meetings; (c) Lab 1, a space for conducting major experiments, filled with a lot of equipment (e.g., incubators, freezers, laminar flow hoods, scales, micro-centrifuges, isotope ratio mass spectrometer, nitrogen canisters, and glassware); (d) Lab 2, a space for filtering and small-scale experiments; and (e) Lab 3, a space for washing glassware and small-scale experiments (Figure 1).

\section{««««« Insert Figure 1 about here »»»»»»}

On the first day of their the internship, Group I, supervised by Nora, participated in filtering in Space A, learned about incubating in Space B, and then conducted bacteria purification in Space C (Figure 1). On the second and third days, the students stayed in Space C to do advanced bacteria purification and antibacterial resistance plating. On the fourth day, students watched Nora in Space D pour a gel in preparation of conducting an electrophoresis analysis and then went to Space $\mathrm{C}$ to this form of analysis. During the entire internship period, students did not work in other locations - e.g., students did not see the chief scientist or participated in a head office meeting. That is, the interns did not come to experience the laboratory as a whole to learn how it functions - as might be the goal for science educators concerned with the nature of science and an understanding of science generally - but, participating in its mundane, everyday, orderly, and unremarkable practice, saw the laboratory through the lens of one experiment.

We observed similar patterns in the other three groups of students who participated in other projects using different equipment. Group II, working on tracking chemicals in aboriginal seafood, used six pedagogical locations (one in Lab 1, three in Lab 2, one in Lab 3, and one in the staff office); Group III, working on pharmaceutical products in municipal wastewater, was situated in two pedagogical spaces (one located in Lab 1, and one in Lab 2); and Group IV, working on household bio-sand water filters, worked in four pedagogical spaces in the laboratory (one located in Lab 1, two in Lab 2, and one in the staff office). That is, there were a limited number of locations where instruction was provided, each involving a characteristic form of language determined by the nature of the experiment, the tasks associated with it, and the location where it happened.

A proper (pedagogical) space for instruction A previous study on the role of a teacher's position in the classroom and the nature of the classroom language showed how distinct locations of the teacher in the classroom were associated with the manner in which he interacted with 
students and his level of control over the language used (Roth et al. 1999). In the present study, we observed how members explicitly defer certain kinds of language (words) to specific physical locations in the laboratory in which they are to occur. Thus, for example, a laboratory technician would refer to teaching a specific technique and suggest that this teaching will be occurring in a different location than the one that they currently occupied. Episode 1 exemplifies how a conversation is explicitly deferred until the group arrives in a location where the language (words) is appropriate. Locations therefore appear to have an anchoring function, providing resources for understanding the relevance of what is being said; and these locations are associated with specific forms of language and words, thereby linking language and world more generally in the way that pragmatic philosophers have suggested (e.g., Rorty 1989). We do not have to wonder about the "meaning" of words but rather how any words find their place in relevant settings (Heidegger 1927/1977).

Episode 1 occurred on the first day of the internship in Space A after Nora has demonstrated a specific filtering technique. Cindy volunteers to be the first student to do the required filtering. At the end of the filtering, Petri dishes are labeled in terms of the sample source. When Cindy orients to writing the label on the front side of her Petri dish, Nora suggests that it is the backside that should be labeled.

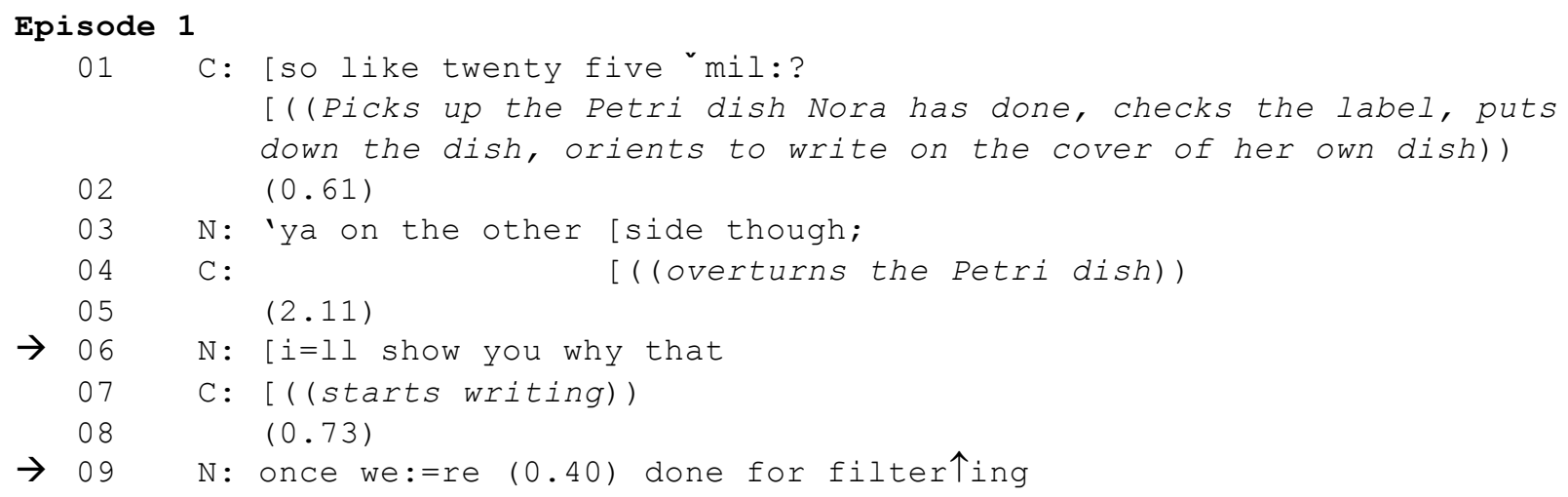

Cindy articulates with rising intonation what is to be written on the Petri dish "so like twenty five mil?" (turn 01) and checks Nora's label on the previously completed Petri dish. Although Cindy has checked Nora's label on the backside of the demonstrative Petri dish, she orients herself to write the label on the front side of her dish (turn 01). By saying "on the other side though" (turn 03), Nora exhibits noticing Cindy's orientation; this makes available to everyone present that Cindy is placing the label on the inappropriate side ("though"). Nora does not talk about the reason for writing the label on the backside of the Petri dish. But, using the future tense, she projectively formulates to be giving an explanation later ("I'll show you why that") and "once we're done for filtering" (turn 09), as if right now were not the appropriate place or time for the explanation. This apparently mundane comment is one of those ways that interaction participants use to prepare each other for what comes next: they project future events. Here, Nora does not provide the explanation about labeling Petri dishes until after the completion of the filtering in Space A. Once all three students have completed filtering their samples, Nora walks the group to Space B to where they continue to work with the Petri dishes (see Episode 2).

This episode exemplifies how a particular form of language was associated with and projected to occur in a particular space. In our study, we observed that each of the four spaces identified (Figure 1) has had its characteristic language that is closely related to the workflow generally and to the artifacts and equipment located there specifically. Words alone and in 
relation to other words and material practices may be taken as tracers - i.e., bits of knowledge, procedures, or tasks - that allow the identification of indexes to forms of knowledge across time and space. We therefore identified the prevalence of certain words within specific locations. For example, the verb "to filter," associated with the practice of filtering and specific sets of actions, appears 25 times during the internship and 21 of these times when the group is in Space A. Another example is that 27 occurrences of the term "ethanol" all occurred in places which have access to ethanol, such as in Space A (i.e., near the filtering facility, 4 occurrences) and Space C (i.e., near the laminar flow hood, 23 occurrences). This is consistent with the understanding of the irremediably contextual nature of "indexical expressions," which bind texts and their con/text (Roth 2010). That is, the language about filter(ing) is significantly more frequent in the context of Space A where the filtering facility is located, because it is precisely here that filter- and filtering-related language makes salient the orderly properties of the work in progress. The same phenomenon can be observed in other groups, for example, in the one that analyzed bioaccumulated chemical elements in fish. Our videotapes show that the term "fish" appeared 46 times during the internship, 41 of which were uttered in the location where they dissected the samples (Group II). Another example is from Group IV, which aimed at creating household biosand water filters. The term of "colony" appeared 28 times during the internship, 20 of which were uttered in the location where they used a microscope to see the pattern and color of E. coli colonies.

In summary, therefore, different physical locations and spaces were associated with different stages in the workflow to which were tied characteristic words, forms of language, and associated practices that can be distinguished from the forms of language and practices typical for other spaces. This is consistent with a philosophical analysis of language, according to which (new) words accrue to existing signification (familiarity) rather than having or obtaining signification (by means of individual or social construction).

The transition between pedagogical spaces - transition repetition promotes cohesion The language of the members to a setting is closely associated with the focal artifacts, material resources, and physical structure of the field. For instance, in classrooms where students learn science by designing artifacts, specific workstations or the electrical outlets became gathering places where a lot of teaching and learning occurs leading to a diffusion of available factual knowledge, language, and tool-related practices (Roth 1995b, 1996); these spaces contrast the general practice where students individually or in groups tend to work on their own bench and with their own equipment. However, a practice that occurs in different locations, characterized by different forms of language as described above, might be experienced as disconnected if the language in one location were not somehow related to the language in another location. Such disconnects are described in the model of a third space in content area literacy, where students experience home language and school subject matter as different, representing a first and second space, respectively (Moje et al. 2004). Another case would be those instances within a science curriculum where students do not experience connections between the language (words) of one unit and those of another (Roth and Roychoudhury 1992). To deepen our understanding of changing forms of participation during an internship, we investigated the relationship between form of language and participants' trajectories through the different spaces.

In the preceding subsection, we show how language and associated practical actions are related to the location in which these naturally occur. In particular, only certain locations in the laboratory, associated with the specific workflow of the technician's project, come to be pedagogical spaces for giving instructions and explanations. However, a broader understanding 
concerning these pedagogical spaces requires understanding the cohesion of communication in and across different spaces, times, and modalities of expression. Such cohesion is important because it is an important mechanism for STEM integration that supports student learning. In the following episode, we exemplify how cohesion between and across locations is produced during a trajectory across different spaces in the laboratory while participants are walking from Space A to Space B as required by the workflow (see Figure 1).

The group completed filtering the samples and ended with four Petri dishes containing bacteria. Nora then picks up these dishes and formulates in a projective manner what will happen in the future: "these samples" are "gonna go into the incubator." The specialized verb formulate makes salient that members to the setting do not just act but use terms that name/describe what they are doing for others. Here, Nora uses future tense (therefore our addition of the adverb "projectively") about something that will occur in a different space, and thereby promotes cohesion between what they have been doing here and now to what will happen at a different place at a future point in time in a different location where they will be because of workflow requirements. There is not just talk in one space and then in another. Part of the talk in one space, which organizes the work in this location, also is preparing for the transition into another space. The transition is projectively organized by the particulars of the workflow in the analysis of the water samples.

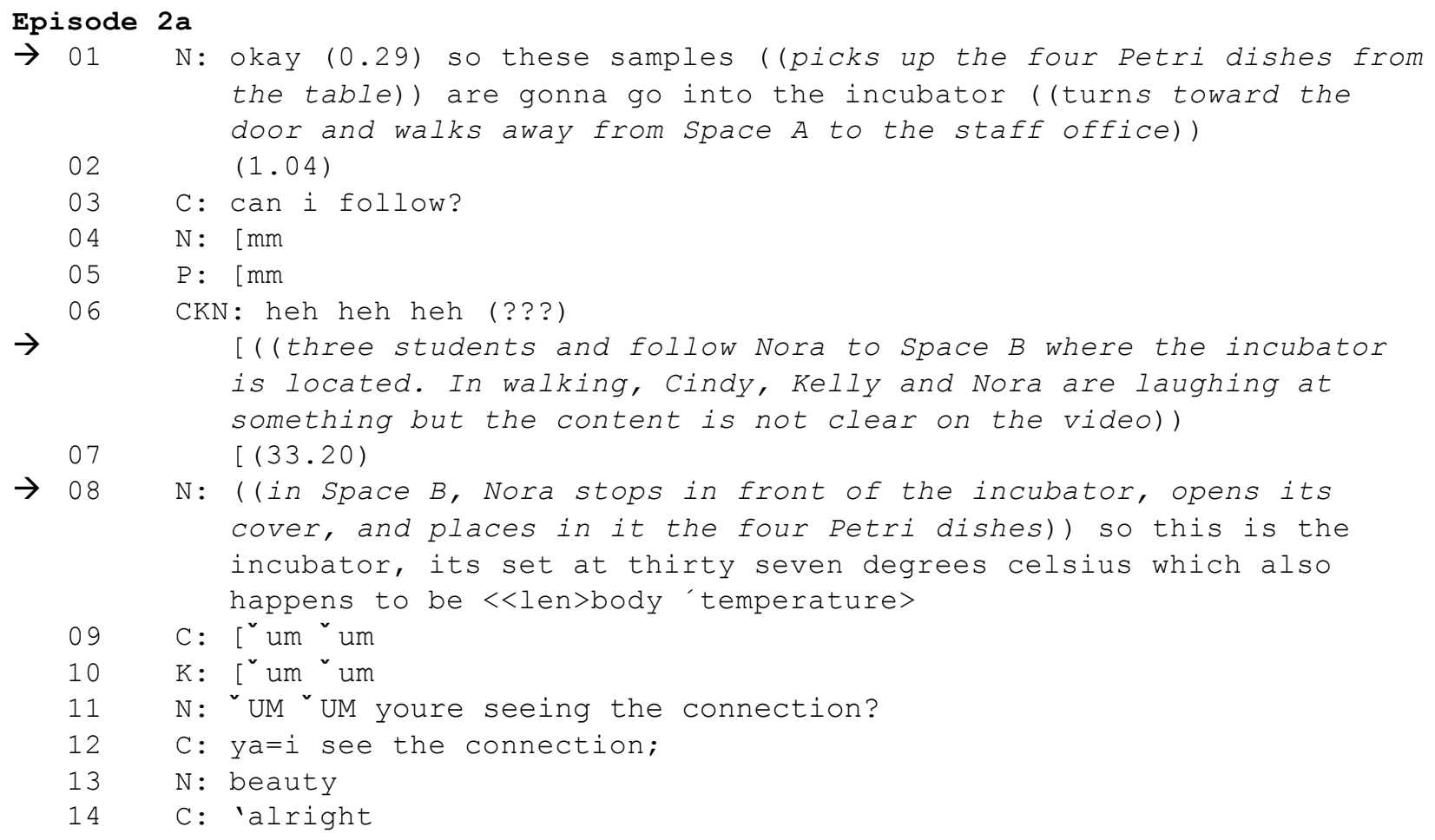

The incubator is located in Space B of Lab 1. In saying "these samples are gonna go into the incubator," Nora formulates the upcoming action and thereby makes of the departure from Lab 2 intelligible. Cindy asks if she can follow Nora. Nora does not explicitly invite students to follow, merely producing an "mm" sound (turn 04). The students, as evident in their lining up sequentially and following Nora past the staff office and into Space B of Lab 1, hear this as an invitation that they accept by walking along. After passing through the door that leads to Lab 1 , Nora stops in front of the incubator, opens it, and places in it the four Petri dishes. Nora then 
introduces the incubator ("so this is the incubator"), its temperature ("thirty-seven degrees Celsius"), and makes a reference to body temperature ("which also happens to be body temperature"). Because the production of "body temperature" is slower than normal and with increased pitch, we can hear an emphasis placed on the word. Both Cindy and Kelly respond affirmatively "um um" (turns 09-10). Nora responds affirmatively with the same pitch contour used by Cindy and Kelly "um um" and asks a question "you're seeing the connection?" (turn 11). Cindy affirms ("ya, I see the connection," turn 12) affirmed as acceptable in the locution "beauty" (turn 13).

In the preceding episode, there is a clear correlation of work spaces, workflow, and language. Thus, as the group arrives in Space B, Nora introduces the "incubator" and describes its temperature setting. Along the trajectory from Space A to Space B, the term of "incubator" marks the end of the conversation in Space A and the beginning of the conversation in Space B. That is, the term of "incubator" can serve as a repetition that promotes conceptual cohesion across two conversations separated by another conversation. One notices the different functions of the repeated terms (e.g., incubator). Although articulated in Space A ("these samples are gonna go to the incubator"), detailed information about the incubator is presented later in Space B. That is, the term of the "incubator" in Space A mainly functions as a projective reference, whereas in Space B it becomes the actual topic of talk. In this study, transition repetitions that contribute to the conceptual cohesion across spaces and times constitute a pervasive feature. This assisted students in developing a sense of continuity rather than being confronted with different materials, practices, and forms of language in the different parts of the field. Thus, in Group II, which analyzed the substances in aboriginal food, the term of "extraction" was used in the transition from Lab 2 to Lab 3. Before leaving Lab 2, the technician uses "extraction" as prospective reference: "Now we will go into the other room for extraction." One minute later when they arrived in Lab 3, the deferred "extraction" becomes a topic for discussion. Because the extraction does not have to become the topic, we use the adjective projective, which anticipates but does not determine a future action. Another example is from Group III, which analyzed pharmaceuticals products in municipal wastewater. The term "GCMS" was used in the transition from the staff office to Lab 1. GCMS is the acronym for "Gas Chromatography Mass Spectrometry," which is an instrument that graphically shows the chemical composition of a sample. Before leaving the staff office, GCMS was used as a projective formulation for transiting to another space (Lab 1): "Now we are going for GCMS." Later, when the group arrived at the GCMS machine, they discussed all features and functions of GCMS. In our observations, the text samples we recorded are sensitive to the space where they occur. Given the association of language and spatial location, it is not surprising that the tight relationship between text and con/text has been noted in previous research (Roth 2010). Even the transitions between the laboratory spaces constitute contexts in their own right - generally permitting conversational topics unrelated to the experiments associated to specific locations.

Location-specific artifact and time formulation function as pedagogical anchors In the previous subsections we exemplify how spaces and their artifacts are related to the instructional language. This finding is consistent with the idea of focal areas that orient members to the physical and social dimensions of the field (Roth et al. 1999). In this second part of Episode 2, we exemplify how spatial aspects of the field projectively organize instructions much in the same way that the physical configuration of a speed card booklet "becomes a representation of the cockpit's memory for both the projected gross weight and the appropriate speeds" (Hutchins 1995b, p. 276, emphasis added); in other words, spatial structures anticipate the temporal organization of 
the content of instruction. After putting the Petri dishes into the incubator (turn 08) as illustrated in the first part, Nora says "so tomorrow" and goes toward a freezer (trajectory from Space B to the freezer, Figure 1). In a similar way, when Nora walks away from Space A, her body orientation (walking away from Space B) can be seen as an invitation for students to follow, which, in following, they accept and thereby concretize as an invitation-acceptance turn sequence. Her body orientation has organized the phenomenally available material aspects of the field. Nora then stops in front of a freezer, opens the freezer, picks up a bag full of incubated Petri dishes, and then returns to Space B. The three students follow Nora to the freezer and then back to Space B. This transition is different than that from Space A to Space B. Because they do not talk "off topic," the students have an opportunity to attend to Nora's actions and the reasons for them (i.e., the invitation to anticipate the future results of these incubated Petri dishes). After they return to Space B, Kelly formulates a question to come: "just a question." "Are we wearing the gloves to protect ourselves from the bacteria or protect the bacteria?" she says; but Nora does not immediately answer other than producing several markers of hesitation separated by pauses.

After answering Kelly's question "protect them from us," Nora then says "tomorrow," again with a louder voice and upward pitch, followed by a statement in future tense, "they'll look something like this." The repetition of "tomorrow" thereby functions as a bridge that connects different timing of language in the same space (i.e., the language 25 seconds ago and the present language in Space B). Similar to the term of "incubator" appearing in Space A (turn 01) and Space B (turn 08), the repetition of "tomorrow" promotes cohesion across different situationspecific forms of language. But unlike the term "incubator," which offers topical cohesion of the talk across the different locations and pedagogical spaces, the term "tomorrow" links different conversations across time but in the same space by projecting what will happen in the future. After making the connection, Nora then picks up a Petri dish from the bag and suggests that "they will look something like this" with her finger pointing to colonies on the Petri dish. In particular, "this" here functions as a demonstrative, which marks the moment at which the context-specific deictic gesture that makes something in the context stand out should be attended to (e.g., Hindmarsh and Heath 2000). Nora goes on to guide students to "see" the different color of bacteria colonies "the blue and the red" that exhibits the reference of the prospective indexical - "this" with a positive comment followed "great fun." Cindy offers up a question "the blue is $E$. coli?" Nora affirms: "the blue is E. coli."

In Space A, we recorded Nora saying that E. coli will "turn blue" after the incubation. That is, although bacteria are not visible to students' unaided eyes in Space A, they will become visible after incubation in Space B. Thus, the conversations about the visible nature of the bacteria colonies are characteristic of the language in Space B. Coherence across theses two locations is produced by the announcement in one space that anticipates the events in another space. Notably, Nora does not introduce the Petri dishes in front of the freezer or along the trajectory; she does so in Space B where the incubator is located, as if the language of the bacteria colonies ought to happen in Space B. Thus, in this instance we observe both a disjunction articulated between two spaces - between what they experience right now and what they will be observing on the next day, as per Nora's formulation - and a resource for cohesion and conceptual integration. What is being done and observed right now is discursively marked as different from what will be done and observed on the next day. But in anticipating that the future action and observation relates to the same object (the language and its contents), there a resource for integration and cohesion is produced. The phenomenon of conceptual cohesion across time in the same space also appears in other groups. For example, the group that monitored the chemicals in aboriginal seafood (Group II) enacted many lengthy procedures in different labs to 
identify chemical composition of samples. Thus, utterances that bridge different practices across time are often used to help students' comprehension of these scientific procedures, such as "you have to wait for hours, for [getting] like 3 millimeters of sample," "what we do at this stage is just wait here until they get all the way down here (figures pointing to a test tube)." Another example is the group that builds household bio-sand water filter (Group IV). Because the project aims to find the best design of household bio-sand filter, the group needed to take time to observe the different effects of different design of bio-sand filters. Utterances that linked different results from different filters across time assisted students to understand the drawn-out process, such as "this filter takes about one day to filter the water sample, and that one takes about two days." In this way, conceptual cohesion was produced across space and within space but across time.

Practices change with the presence of interns So far we have treated the laboratory as a stable cultural field into which the students come and experience science in its everyday ways. This actually is consistent with the way communities of practice have been articulated, where newcomers are understood to move along a trajectory from peripheral to core participation. Many scholars do not tend to think about a field as changing with the arrival of a newcomer or intern; but to understand practices dialectically, we must think of the community-of-practicedefining field as changing (Roth and Lee 2006). Knowing and learning then are understood as knowledgeability, the "flexible process of engagement with the world" (Lave 1993, p. 13) which itself is understood in terms of "changing processes of human activity" (p. 12). Our videotapes recorded during the 6 months before the high school students arrived show that the technicians' practices changed with the rearrangement of spatial relationships that resulted from the high school students' presence and with the pedagogical need of allowing the students to see what their mentor was doing - consistent with the changing spatial relations between teacher and class as soon as other teachers take part in a lesson (Roth et al. 2005). That study showed that the spatial movements of coteachers, who co-inhabit the same space, not only are complementary but also entrain new teachers into particular movement and conceptual patterns.

In this study, the students did not experience exactly the same practices that they would have had as flies on the wall that leave the setting relatively undisturbed. That is, although conceived as a form of participation in "authentic practice," that is, in the everyday work of science, we did not follow others (e.g., Schwartz et al. 2004) and conflate the internship with the real thing that occurs in the students' absence. We consider the internship experience to be a living and lived "reality sui generis" (Durkheim 1919, p. 12, original emphasis), that is, a phenomenon in its own right that needs to be studied as such. The physical presence of the students changes the spatial configuration and orientation observable in the laboratory when students are absent. What the students experience and learn in and through participating, therefore, is different from "normal." Because we did not observe the participants making this learning explicit, it is likely occurring in the form of a learning-in-praxis-typical pedagogy of silence, which emphasizes tacit modes of transmitting practices (Bourdieu 1992). The interns therefore appropriate these experienced practices rather than the ones that are typical for the laboratory members in the students' absence. For example, our ethnographic study reveals that Nora tends to stand up or sit on a chair while working under the laminar flow hood. However, when Nora demonstrates her work to students, she actually squats down (Figure 2a). The physical arrangement of the laminar flow hood between two big tables required the observing students to be behind Nora; her squatting enables observation (Figure $2 b$ ). When the students subsequently enact the technique individually they all emulate Nora, as if this position were normal or required for this technique 
(e.g., Figure 2c). But there are instances, as in the following episode, where members remark that a form of action is not normal or required. Episode 3 is initiated by Kelly who asks Nora a question about the function of the "old case" when Cindy cultures bacteria in front of the laminar flow hood (Figure 2c).

««««« Insert Figure 2 about here »»»»»

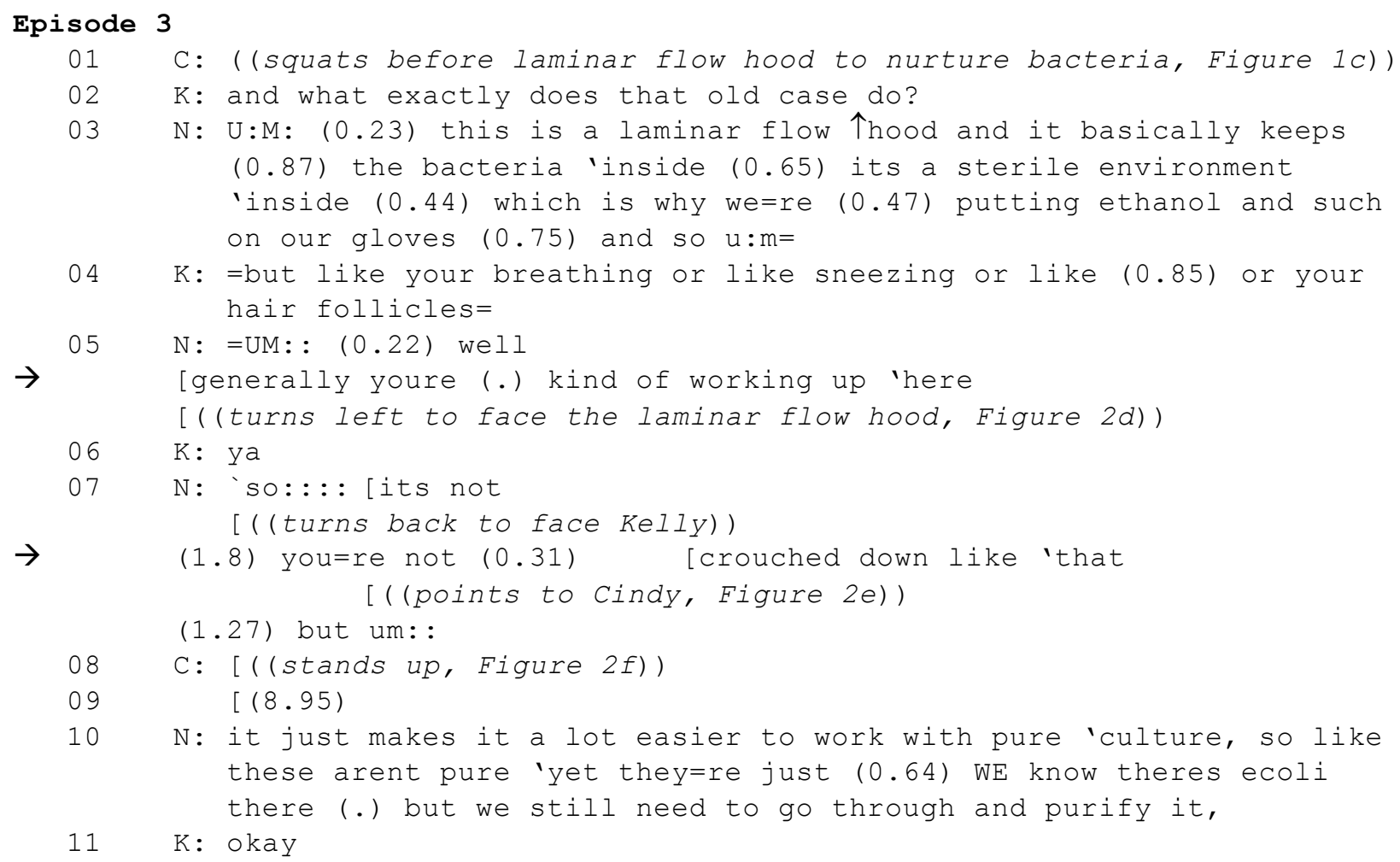

In this instant, participants mark their awareness of the contradiction between the squatting position Nora and the students have taken and its subsequent description as inadequate. There is a long silence ("8.95" [turn 09]) that is much longer than the 0.7 -second silence typical for teacher-student conversations (Tobin 1987), before Nora continues speaking to this topic (the videotape shows that while Cindy labels her Petri dish, others just stand there). It is this long silence against the unfolding conversation that marks the presence of the contradiction. As there is no verbal response, Nora continues describing their current practice ("it just makes it a lot of easier to work with pure culture," "these are not pure yet" [turn 10]) and future steps ("we know there are E. coli there, but we still need to go through and purify it" [turn 10]). Nora thereby provides a rationale to justify her previous squatting position. It is as if that it were okay to squat now because these bacteria are not "pure yet," so it has no harm if we take a squatting position. Kelly then accepts this explanation ("okay" [turn 11]). The mediational influence of the interns" presence on a technician's practice was also observed in other groups. For example, the technician in the group that analyzed pharmaceutical products in municipal wastewater (Group III) indicated that he "normally" sat closely to the GCMS during the entire day to do the accurate calibration, rather than "standing up" as he was with these high school interns. The technicians in the group that focused on identifying chemicals in aboriginal food expressed that it usually took technicians months to analyze samples (Group II). To teach these high school interns, the technician shortened the whole process into hours ("Today is really long. The whole process, 
usually it takes two weeks to analyze most of this. I tried to do everything in three hours today").

\section{Spatial relations project temporal aspects of practice}

Workplace studies such as those reviewed in the background section show that spatial relations - such as that on the bridge of a navy vessel or in the cockpit of an airplane - organize the temporal aspects of practice. In the preceding section, we describe how spatial structures shape language and practice generally. Previous research has shown that "the display of equipment on the [laboratory] table was 'a practical account of the present state of the experiment" (Lynch et al. 1983, p. 229). As a consequence, the "arrangements, and their orderly reflexivity to the experiment's unique 'lesson' [act] as mnemonics, or as records of 'activities-sofar' in a project of action" (p. 229). That is, current spatial arrangements are "natural" indices to what comes next in a sequence of operations. But members to the field still have to find the relevance of the indices: The index is recognized as such precisely at the instant that its relevance is discovered. It has been noticed that actions are not built on words alone (e.g., verbal instruction) but also configured by the dynamic semiotic fields that participants demonstrably orient to. That is, participants act in terms of the locally relevant configuration associated with workflows. Perception and action thereby come to be inextricably intertwined. Although the relation between cognition and the spatial organization of workplaces (e.g., Hutchins 1995a; Scribner 1984), and although there have been early attempts in school science to identify the relationship between the spatial organization of classroom and learning (Roth 1996), relatively little continues to be known in the context of school science about how action sequences are configured by spatial relationships of people and artifacts. Thus, we are particularly interested in the relation of the temporality of action sequences and spatial structure. In the following, we present four ways in which physical structure called for specific next actions across the four groups we observed: (a) distance of artifacts; (b) artifact state; (c) orientation of artifact; and (d) body orientation. The temporal organization arising with spatial structure, therefore, contributes to cohesion and internal logic of actions, as students could take the appropriate next step without having to be explicitly instructed so. The relevance of this aspect of our research derives from the fact that high school students often do not know what to do and what to do next when doing traditional ("cookbook") laboratory exercises (Hofstein and Lunetta 2004). If there are ways that their laboratory spaces could be configured such that next steps can be more easily identified smart spaces - then this would aid students in completing the manual aspects of their laboratory tasks and allow them to focus more on the underlying conceptual aspects. That is, the four dimensions we describe and exemplify are possible starting points for redesigning laboratory instructions and manuals.

The scientific project on which Nora works at the time aims at identifying bacterial sources in water samples by means of DNA sequencing. This involves many techniques, instruments, tools, and procedures during the purification of the DNA samples. After receiving the water samples collected by other agencies, the first technique is to filter the water sample to collect bacteria using paper filters, a pipette, and a pump facility. The pump facility includes three main components: a pump motor, a pump filter constituted by a conical flask that holds the filtered water and a cover that collects water into the conical flask, and a pump hose that connects the pump motor and the pump filter to pump out the air in the flask. Therefore, the technique of filtering includes several main steps: (a) gripping a paper filter from a package; (b) putting the paper filter on the conical flask; (c) covering the paper filter with the pump filter cover; (d) using the pipette to collect a water sample into the cover (and then flows into the conical flask); (e) turning on the pump motor; (f) removing the paper filter into one Petri dish; and (g) labeling the 
Petri dish (e.g., information about collecting location and the amount of sample water filtered). Filtering is a sequentially constrained procedure that requires the precise temporal alignment of operations. Nora first demonstrates how she filters and then invites students to filter individually. In the following episodes, we exemplify these issues in the case of a student (Cindy), who learns to filter a water sample on the first day of the internship. Cindy and Nora are positioned where their body orientations allow an overlapping space for them to have equal, direct, and exclusive access to the artifacts on the table. The following analyses exemplify how the spatial relationship of a setting projectively organizes action sequences. In addition to the observations in Group I, we also provide relevant data from Group II (chemical components in aboriginal seafood) when it was preparing the extraction steel cells for the chemical extraction.

Distance of artifacts as temporal marker How do people act when they are situated among numerous unfamiliar tools and artifacts in a complex environment? How do they use the unfamiliar tools? The following episode exemplifies how the spatial order of artifacts may project the sequence of situated actions that interns enact: spatial organization acts like a plan or recipe that organizes the actions. For example, the process of filtering bacteria from water samples includes Petri dishes, water sample bottles, a pump filter, one pair of tweezers, one pipette, one box full of paper filter packages, one tissue box, one ethanol bottle, and a pump hose connected to the pump motor. The physical arrangement of artifacts and tools may be such that it projectively organizes the correct operation to be completed. In this episode, Cindy is about to filter the water sample. She formulates the amount of water to be taken ("so just take one twenty five?") and simultaneously grasps the pipette.

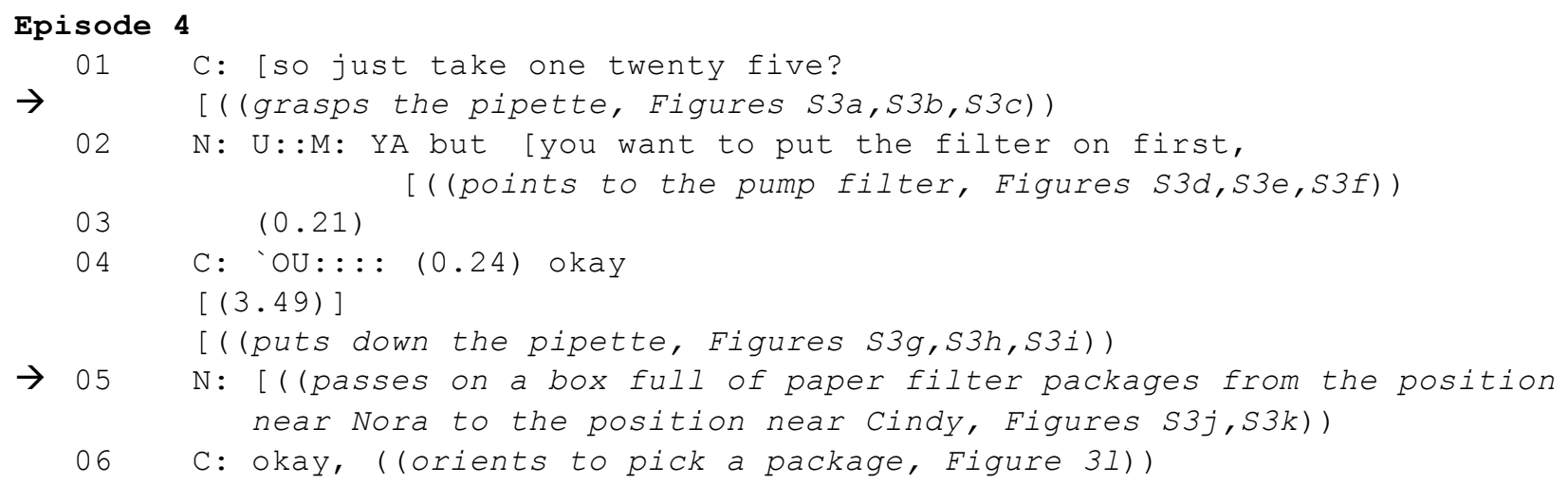

««««« Insert Figure 3 about here »»»»»

Here, there is an asymmetrical relationship between Nora's statement and her gesture of pointing. She says "you want to put the filter on first" (turn 02) but her finger does not point to "the [paper] filter" that is closer to Nora. On the contrary, her finger points to the opposite direction where the flask is located. That is, the language alone does not allow us to understand the function of the pointing: it must be seen as embedded in a situated practice (Goodwin 2003a). Nora's pointing finger is located in Cindy's line of sight to the configuration on the bench. As a result, Nora's statement may be heard as: "You want to put the filter on [that flask ((pointing))] first." This pointing here is one form of a symbolic gesture (e.g., pointing) that is built through the conjunction of talks, gestures, and the material structure in the environment (Goodwin 2003b). Even though Nora does not formulate what she is pointing at, students do not request clarification. Rather, a confirmative "okay" (turn 04) marks Cindy's understanding of the instruction provided in verbal and gestural terms. Cindy puts down the pipette as if she 
recognized that it was not the right time for using a pipette. Nora relocates a box full of paper filter packages to a location that is closer to Cindy (turn 05). Cindy orients to pick up a paper filter package and said "okay" (turn 06).

In this episode, Cindy grabs the closest tool to begin the task. The way she grasps the pipette is fitted to the affordance of the pipette design. Cindy's grasping action is projectively organized by proximity and the grasping operation that the pipette affords. In response to Nora's pointing and formulation, Cindy places the pipette in a spot some distance from her. Simultaneously, Nora relocates the paper filter box to a place closer to Cindy. The resulting spatial order of filter box and pipette thereby corresponds to the required temporal sequence of operations. Ordering the tools and equipment in space allows Nora to sequence the operations so that the correct order of steps that complete a proper filtering action is executed. That is, whereas past research has shown that students have problems with the proper sequence of tasks to accomplish the purposes of an investigation (Hofstein and Lunetta 2004), this case shows how a simple spatial organization of equipment can get students to enact an appropriate sequence of actions to accomplish a step in the unfamiliar procedure. No further instructions are then required to guide an intern unfamiliar with the field through the complex sequence. Another example of this phenomenon derives from Group II when students were preparing a fish sample for chemical extraction. Students were presented with the sample and an extraction steel cell (a cylinder) in front of them. After their technician's demonstration of how to place the sample in the cell, the technician invited students to do the same. The first step for students is to pick up the fish sample and then place it. However, the student first oriented to the extraction steel cell and then to the fish sample. The technician then corrected her ("no, the fish first") and approached the fish sample so that it was closer to the student than the cell. Here, we can see again that the distance of artifacts serve as a temporal marker that structures the practice.

Artifact state as temporal marker The physical state of an artifact is an important marker for the next operation to be completed in the work of short-order cooks doing multiple orders simultaneously (Agre and Horswill 1997). That is, the physical state of an artifact, resting in a particular location, projects what is to be done next and where. That is, cooks do not have to memorize the steps or think about where they are in the course of preparing a meal but the present state (order) of the kitchen and location of the meal-in-progress determines for the competent short-order cook what needs to be done next to the meal. But they can do so only when they are familiar with the kitchen. This familiarity is problematic, however, because it tends to hide the "incredible organizational thing that the transparent embodied achievement consists of: the unremarkable "we can do it again"” (Garfinkel 2002, p. 216, original emphasis). In this study, as exemplified in Episode 5, we observe how the artifact state becomes a temporal marker that assists in the overall organization of action sequences. After filtering a water sample, Nora formulates the next step (turn 01) and, together with pointing, thereby invites Cindy to put the paper filter into one of the four Petri dishes on the table.

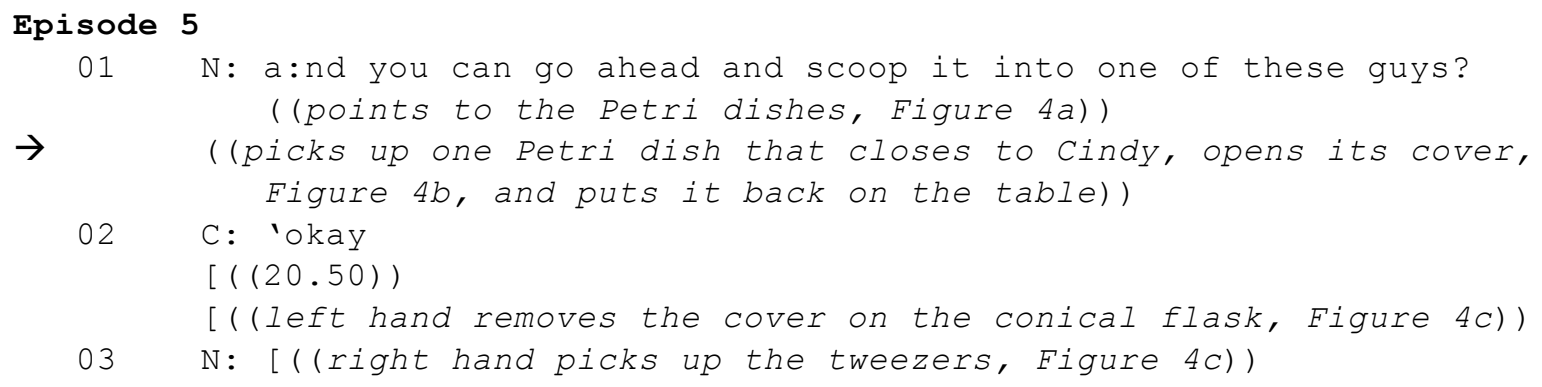




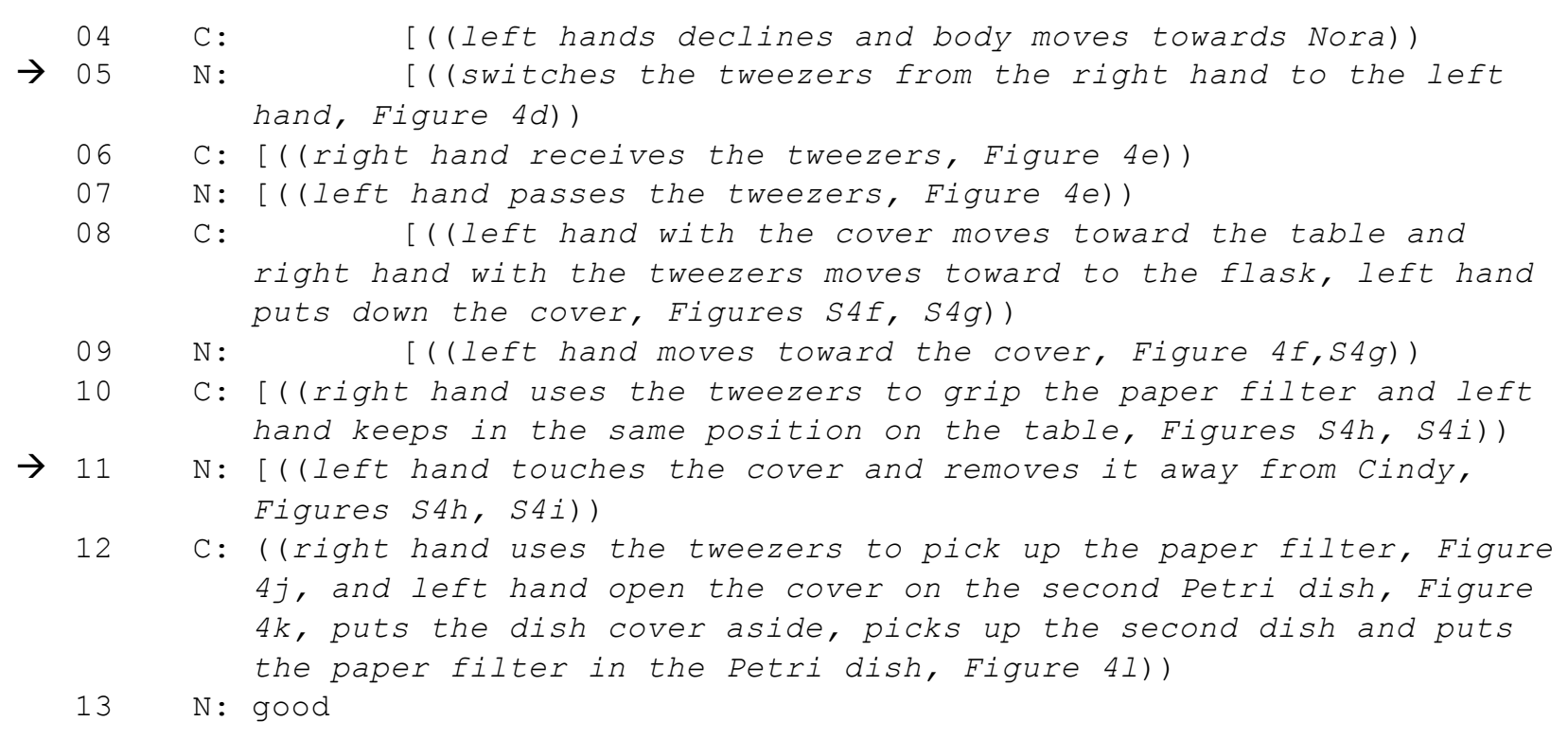

««««« Insert Figure 4 about here »»»»»

Nora transforms an artifact (i.e., a Petri dish) from a covered state to an uncovered state. The state of the uncovered Petri dish signals its readiness for Cindy to act upon and to mark the spatial and temporal order for the next action: to "scoop" (turn 01) the paper filter into "this" dish "first" rather than somewhere else. Nora picks up a Petri dish that is closest to her among the three undone Petri dishes: The spatial order of the Petri dishes projectively organizes what Cindy has to do next - choosing this rather than another dish. Here, both the state and the distance of the Petri dish orient Cindy to pick up a "right" artifact among many. Moreover, when Cindy uses the left hand to remove the filter cover, Nora picks up the tweezers thereby marking the-next-thing-to-use for Cindy. She switches the tweezers from her right hand to the left hand as if she has prepared the tweezers in a state that is ready for Cindy to receive easily. That is, when Cindy turns, Nora's left hand meets Cindy's right hand that is the only available hand for receiving a tweezers because Cindy's left hand grasps the pump filter cover. Because Nora has switched the hold on the tweezers, Cindy can now act smoothly in a proper sequence.

The positioning of the tweezers is a salient illustration of "recipient design" that organizes what interaction participants do and say. Following Nora, Cindy displays a recipient response. When Cindy places the pump filter cover on the table, Nora removes it from her hand (turn 11) to a more distant location. Nora thereby moves the artifact irrelevant-to-the-next-step away from Cindy thereby indicating that Cindy will not need it in the near future. Thus, an apparently mundane, unremarkable operation - placement of a cover in a distant location - configures what the intern can/may/will do next. It constitutes a form of non-explicit, immanent instruction that shapes what the interns learn. We also observed this phenomenon when the technician in Group II guided students to prepare the fish sample for the extraction. One of many steps for the preparation is the opening of the caps and the placement of the sample in the cells. Before students' actions, the technician opened one cap of one extraction steel cell: a "ready state" for receiving the fish sample. One student then put the fish sample into the uncovered steel cell rather than other steel cells. That is, this uncovered steel cell is an artifact relevant-to-the-nextstep, a temporal marker that projectively structures the next action (here placement).

Spatial orientation of artifact as temporal marker Our analyses reveal that the orientation of an 
artifact can also serve as a temporal marker. Episode 6 repeats Episode 1 but now we focus on how the orientation of a Petri dish orients Cindy what to do next. After placing the filter paper into a Petri dish (Figure 4l), Cindy picks up a pen and checks with Nora what information is to be written on the dish ("so like twenty five mil" [turn 01]). Before Cindy begins to write, Nora first produces an affirmative "ya" but then formulates "on the other side though" (turn 03) while pointing to the Petri dish (Figure 5d). Cindy is right in a sense that she needs to write down "twenty five mil" but on the backside of the Petri dish rather than on the front side. Cindy then turns over the Petri dish and starts to write (turns 04-06).

««««« Insert Figure 5 about here »»»»»

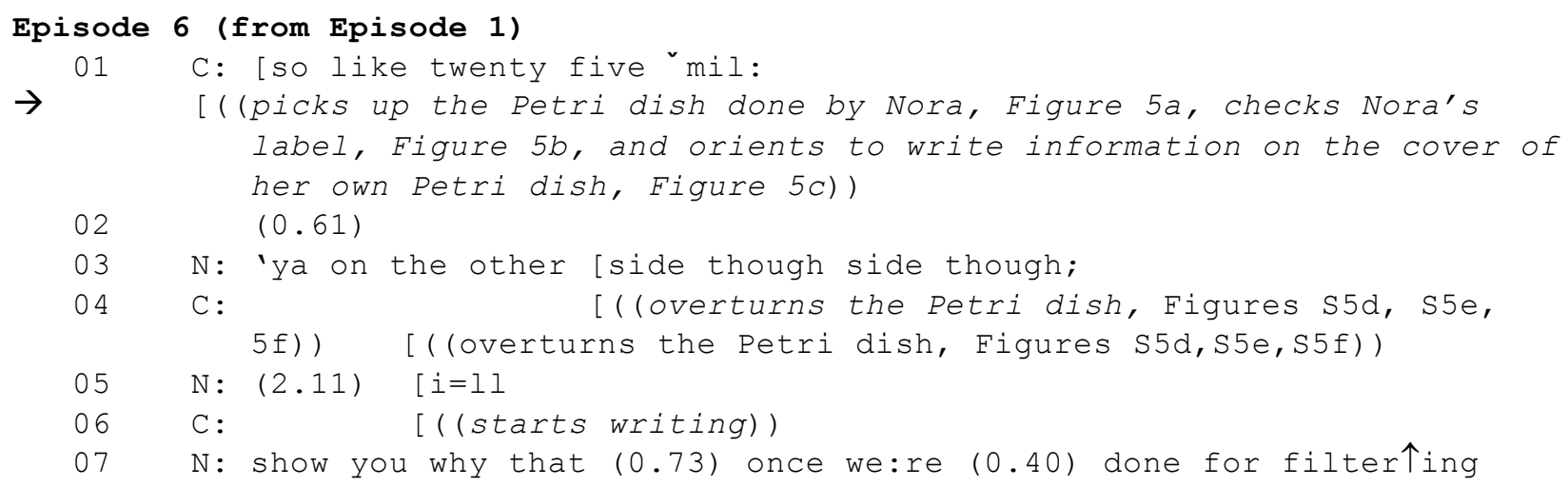

In this episode, Cindy orients herself to write the label on the front side of her Petri dish even though Nora has labeled hers on its backside. That is, Cindy orients herself to labeling the source information on a surface of the Petri dish closer to her. Not unlike in other practices where the distance projectively orients to what is to be done next, the spatial orientation of the artifact invited one rather than another operation (labeling). Similarly, in Group II when students were to write the weight of the fish sample on the extraction cells. Students initially wrote on the top of the extraction cell. However, the technician then explicitly told them to place the label at the bottom of the cell. Again, the orientation of an artifact served as a temporal marker that projectively oriented future actions.

Body orientation as temporal marker Body orientation with respect to other physical features in a location is an important aspect of communication that contributes to the sense of what is said. The coherences of any phenomenal social/material field are achieved by "the details of positions and placement - the positioning work of body parts like fingers, eyes, feet, heads, lips, chins" (Garfinkel 2002, p. 210). We show above how students follow Nora as a consequence of her changing body orientation, taken as an invitation to move from one setting in the laboratory to another, without further verbal formulation. Also, Nora's body orientation changes the spatial relationships within the setting, which becomes a resource for Cindy to produce an appropriate sequence of actions. As Episode 7 illustrates, body orientation may also be used to project the order within an upcoming sequence of operations. After picking up one paper filter package from the box (Episode 4, turn 06, Figure 31), Cindy employs the tweezers to pull a paper filter from its package. However, she rips the paper filter together with package. She succeeds on her second try but then pauses. A series of gestures and orientations on the part of Nora, projectively organizes what Cindy has to do next. 


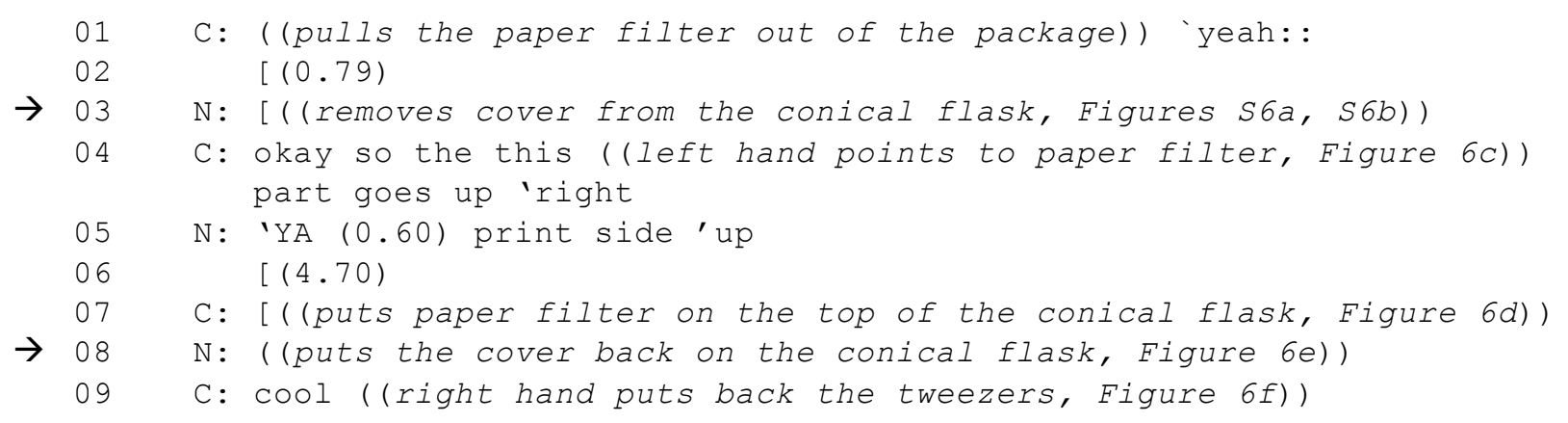

««««« Insert Figure 6 about here »»»»»

In this episode, Nora's body movement is closely associated with the sequencing of Cindy's actions. Removing the cover allows Cindy to see "where" to put the filter paper. Because the cover now is removed, Cindy may proceed in the sequence of operation that will accomplish the filtering: the placement of the filter comes before any other step. In a similar way, re-placing the cover means that this operation is completed so that Cindy can now release her tweezers. Nora's movements function as indexes that projectively organize Cindy's sequencing of operations that together achieve the goal of filtering. Someone familiar with an action sequence may produce indexes - e.g., by means of body orientation - that projectively orient interns to enact a series of actions that constitutes a complex practice. The significance of a movement for the projective organization of next things to be done depends on the context. Thus, in Episode 2, Nora's changing orientation was reified as an invitation to follow her into another room, whereas in Episode 7, the body movements (e.g., removing a flask cover) projectively organized the temporal unfolding of actions in the local context (e.g., Cindy's orientation to the filter paper that goes into flask). Similarly, in Group II the technician's pointing gesture led students to work with the extraction, tending a sample to students led them to do the next step in its processing, and the body facing the extraction cell oriented students to do the relevant next action with it. In each case, the body orientation became a sign for what to do next, allowing the interns to move through the practice in a rather smooth fashion despite being new to it.

\section{Spatial relations, participation in real science, and science learning and instruction}

Technology and good curriculum design alone do not inherently lead to talent and learning (Barab and Plucker 2002). The literature these authors reviewed suggests to science educators to change their focus from individual constructions to think about persons-in-situations and to the fact that learning arises precisely at the nexus of people and settings. An important component of any cultural field is its spatial organization (Bourdieu 1980). It is the fit, then, between individual and the cultural field, including its physical structures, that leads to the optimization of competence and talent. Although science educators have shown interest in the situated nature of cognition (e.g., Case and Jawitz 2004), they generally have not attended to the way in which physical spaces might be structured to support learning. This ethnographic study was designed to better understand the relationship between space and changing forms of participating in scientific practices by finding answers to two questions: "What are the relations between the spatiotemporal organization of a laboratory and the language between its normal inhabitants and the interns that instruct the former?" and "What are the relations between the spatial organization of the laboratory and the temporal sequencing of interns' actions?"

Our study results show how spatial relationships are related to content and structure of teaching and learning while high school students participate in a world-leading science 
laboratory. In Episodes 1 through 3, we exemplify how the spatial organization relates to specific forms of language and practices. In Episodes 4, 5, 6, and 7 we exemplify how (a) the distance of different artifacts, (b) artifact state, (c) spatial orientation of an artifact, and (d) body orientation serve as markers that orient interns to next steps to be completed in required action sequences. In these episodes, therefore, the reorganization of spatial relations allowed high school students to participate in complex practices in unfamiliar laboratory settings. That is, the spatial configuration has "design properties that use the intrinsic properties of a representation to force a specific behavior upon the person" (Norman 1991, p. 34). This allowed our interns to participate in the practices without having to learn everything beforehand. Aspects of the material field thereby functions like instructions. This is actually the way in which much of apprenticeship learning functions, where newcomers first become familiar with a setting before they learn to understand it conceptually - in fact, we can only understand something that we are already familiar with so that all explicit understanding is a derivative of practical understanding (Heidegger 1927/1977; Marx/Engels 1958). In this very sense, cognition is both situated and distributed in the laboratory. Science educators might think about designing instructions extensively using drawings and diagrams that make spatial relations on the laboratory bench more explicit - in the way furniture assembly instructions often do - and thereby organize projectively what students will do and when. That is, rather than using verbal instruction that abstracts from the spatial organization, diagrammatic representations that preserve spatial relationships may decrease the load on students to translate the contents of laboratory manuals into real courses of actions in the laboratory. We are not suggesting the use of traditional flow charts, however, which abstractly (using words and boxes) represent a temporal relation. Rather, we are thinking about representation showing iconic images of spaces and things much like the instructions that come with furniture (e.g., IKEA) that buyers themselves have to assemble. We anticipate that science educators might observe a greater reliance on indexical gestures and physical orientations - much in the way some people turn geographical maps to facilitate orientation - to increase the opportunities of making connections between representation and actual state of affairs.

Our study exhibits the intimate relation that exists between language and the spatial relationships of the setting in which it is produced (con/text). This intimate relation is a concrete instantiation of the pragmatic philosophical stance on language, according to which "the boundary between knowing a language and knowing our way around in the world generally" (Davidson 1986, p. 445-446) has been erased. In particular, certain locations appear to be more opportune for instructional language. Thus, the technicians tended to instruct students in locations that supported making sense of instructions and explanations; these locations were closely related to the workflow of their project. For example, during the whole internship period, Nora provided instruction only in four specific locations rather than other possible locations. Similarly, Groups II to IV worked in 6, 2, and 4 specific locations in the laboratory but not in others. That is, pedagogical spaces are closely associated to the location of the artifacts and tools relevant to an experiment. Therefore, students do not encounter and experience laboratory science as such, in a general and generalized way, but only in and through the specific sites and tools pertinent to a particular experiment. That is, we take what the students come to engage in as a social phenomenon sui generis that needs to be understood as such. But what we can learn from this study that can be transported to school science laboratory setting concerns the role of spatial organization in the sequencing of patterned actions - i.e., (scientific) practices - plays during the learning process. Moreover, the idea of pedagogical space may question the very epistemology underlying schooling, which institutionally embodies the notion of (scientific) knowledge as 
independent of the location and as teachable at any time in any place.

This finding has important implications for science education, where pre-lab instructions and explanations often occur in places other than the laboratory itself. Some science educators use the concept of "explicit instruction," which "models, discusses, and distinguishes between the skills of [scientific inquiry] . . the cognitive outcomes of [scientific inquiry] . . and the pedagogical applications of [scientific inquiry] (Gess-Newsome 2002, p. 56). Others propose using hierarchical task diagrams (e.g., flow charts) for modeling laboratory procedures. All these approaches presuppose explicitness of what is to be done rather than building on the implicitness and situatedness that characterizes competent practice. Since space can projectively organize where instructions might happen and what needs to be done, science educators should seriously consider how to design instructional spaces so that these enhance the intelligibility of the pedagogical language. For instance, educators might want to ascertain a sufficient size of these potential pedagogical spaces for the number of participating students. Moreover, science educators might organize pedagogical spaces to facilitate the fluency of pedagogical language by rearranging the relevant artifacts in terms of the sequence of the (scientific) instructions associated with the intelligibility of the workflow requirements. Whereas organizations such as the National Science Teachers Association have programmatic statements about the need for laboratory activities and the organization of laboratories (e.g., "adequate facility," "adequate storage space," or "laboratory occupancy limits" [NSTA 2007]), they do not have recommendations for the organization of smart spaces. Reviews of science laboratory instructions (e.g., Hofstein and Lunetta 2004) have failed to recognize the importance of spatial organization and competent practices. They also have failed to make recommendations to the design of laboratory instruction that parallel those that designers of everyday artifacts make (e.g., Norman 1991). Such recommendations would explicitly relate spatial configuration of laboratory equipment and the learning of scientific practice. It is especially necessary in cases such as ours when the newcomers to a setting want to participate in an unfamiliar field. How to design a "smart space" that can help teaching and learning is important for educators and policy makers especially given the increasing amount of technology.

Our study helps us to think about how to design a smart space for students, because spaces are themselves agents for change and changed spaces will change people's practice (Joint Information Systems Committee 2006). For example, rather than having high school students set up their own experiments, one might envision them to learn working with ready-made set-ups until they are familiar with the field. These set-ups are organized so that the spatial order of the equipment projects the temporal organization of the task: Instruments and materials closer to the students are to be used earlier than those that are farther away. The resulting changes should project further actions, such as when a test tube, having rested prior to use on the right, will end up on a rack to the left, where it might project the future cleaning actions. Students could be introduced much in the same way as the interns in the laboratory we observed; this could occur during a pre-lab introduction. Only once students are familiar with the workflow, they are directed to make explicit the instrumentation and its composition. This appears to be the ordinary, everyday way in which humans come to learn (about) tools, which they first encounter in use and then conceptualize when normal use is impeded.

In this study, we also identify repetitions that occur across transition, which afford the discursive cohesion across space and time and thereby provide resources for and contribute to the integration required for understanding STEM concepts. The use of transition repetitions that tie current to future actions in different spaces can serve as pedagogical resources for achieving cohesion and integration. 
The presence of interns forces us to theorize activities we observe in a different way, because the endogenous practices of the field change. A new form of human activity is brought about, leading to new learning opportunities on the part of all participants (Engeström 1987). In Episode 3, we show that the presence of the high school students changed how Nora worked under the laminar flow hood. As if following the principle "Do as I do," which characterizes much of learning in practice, the high school students crouched down in the way that they saw Nora work. In the present instance, no harm was done because the deviation from normality was made explicit as a topic of talk. The difference between daily practice and demonstration thereby was made salient even though in other situations, participants to the setting may not become aware of it. To design an appropriate teaching space, science educators might want to consider how spatial configurations of the place of learning afford or interfere with the apprenticeship in a practice. A study of science teachers in training shows that the coordination of the movements of new and experienced teachers afforded the former to learn appropriate positioning in the classroom with concomitant mediating influence on classroom discipline.

Our analyses show how spatial organization projects into the future the temporal organization of upcoming tasks. Thus, Episodes 4 to 7 exemplify how sequences of operation are indexed by material aspects of the field - including the distance of the artifacts, body orientations, artifact states, and the orientation of artifacts. These aspects serve as markers that indicate what is to be done next. This reminds us of the story of a congenitally night blind person, who placed her pots, pans, ladles, and other utensils required for certain recipes so that the spatial order of the implements required for a particular recipe projected the temporal organization of the tools as required by the recipe (Garfinkel 2002). Here, the person herself produced a spatial order to project the temporal order of her actions. In our case study, however, the teachers rearranged artifacts and used body orientation to guide students' actions without verbal instruction. Thus, the technicians designed the spatial relationship around the learners, the recipients of instruction. In a sense, the spatial reorganization can support newcomers to a field much like well-designed artifacts projectively organize their use: A doorknob suggests turning whereas a door handle invites pushing down; placing the dial knobs on a stove top in the same geometrical configuration as the heating elements increases the match between intended and actually heated element. In the same way as well-designed artifacts, well-designed spatial organization enables participation in a practice at a higher level. In other words, it is possible to create a zone of proximal development through spatial-material arrangements. This requires an interactional space between residents and newcomers to access artifacts simultaneously. The residents can then freely scaffold the newcomer's practice physically when needed. Thus, our study allows science educators to think explicitly about how to guide students through the physical organization of the learning setting without taking away their sense of agency.

\section{For the design of smart spaces to achieve participation and science fluency}

Studies that review the state of the art of science education in and through laboratory activities point out the cookbook nature of many activities (Hofstein and Lunetta 2004). Science teachers also know that even following instructions in such laboratories is demanding, leading students to query whether they have correctly followed the instructions and, thus, got all their steps right (Amerine and Bilmes 1990). In the present study, we show how the spatial organization of the laboratory bench and the laboratory as a whole provides an immanent order to the sequential organization of the task, freeing students to think about and focus on other aspects of their experiment. This is particularly important in the context of school science, where students do not spent extended periods of time working with the same equipment, procedures, 
and tasks but, following the constantly changing curricular topics, are continuously required to learn new skills and procedures. Our study suggests that an appropriate spatial organization facilitates students' engagement in complex action sequences even though, and precisely when, they are unfamiliar with a particular experimental procedure.

Our study identifies important functions that the spatial organization has for participation in, and therefore learning of, science-related practice. We encourage designers of science curriculum to think not only about the content but also about designing smart spaces that afford participation and learning. Such spaces would allow students to become familiar and fluent more quickly - such as the blind person in her kitchen - and, if required, aspects of the newfound competence could be made the object of reflection (though this is not what scientists generally do as long as their practices work). This would allow teachers and students to incorporate and re/organize space intelligently to simplify their tasks and increase the time available for reflection on concepts. For example, the equipment required for an experiment could be physically organized in a way so that every subsequent step in the workflow is projectively organized by its particular placement of tools, instruments, and artifacts. We anticipate that design experiments, where spatial organizations are tested in the course of a curriculum, not only will confirm the results presented here but also lead to the identification of additional ways in which spatial organization mediates knowing, teaching, and learning science. Drawing on design experiments would allow researchers and teachers to experiment in situ with various configurations of materials, locations, and people and test their effect on learning process and outcomes. They would thereby test empirically and find out, as Roth et al. 1999 have done when they rearranged the physical location of students, how such physical changes affect participation and learning. However, we also recognize that no instruction manual, however well designed, will overcome the "marvelous incongruous property that users can come upon as cause for complaint" (Garfinkel 2002, p. 205): the "in vivo witnessed incompetence of the text" (p. 205) to unambiguously specify how to act. Instructions are inherently incomplete, a fact that is without remedy.

In this study, we followed students through their internship experience, which comprised a total of 10-16 hours depending on the group. Some readers may think about this as a limitation. But this is not the case, as our interest is in studying the role of spatial relations in changing participation. To study this phenomenon, we sought out a perspicuous situation that would make visible what ordinarily goes without being noticed. Thus, it has been suggested to us that good classroom management involves cues of the kind we describe in this article. The whole agenda of ethnomethodology, which informs our work, is to make salient the normally hidden structures of practical actions in mundane, unremarkable, everyday work practices that make our world as witnessably ordered as it is. To inform science teachers and science teacher educators about how to draw on spatial relations for assisting student learning, the embodied work required needs to be described and understood. Based on Vygotsky's (1989) diction that any higher-order psychological function exists as a social relation first, we would anticipate that the students would become as fluent as any one of the five laboratory assistants involved in our project. This, too, should be taken as an expectation that requires testing in an appropriate design experiment.

\section{Acknowledgment}

This research was supported by a grant (to Roth) from the Natural Sciences and Engineering Research Council of Canada.

\section{References}


Agre, P., \& Horswill, I. (1997). Lifeword analysis. Journal of Artificial Intelligence Research, 6, 111-145. doi:10.1613/jair.342

Amerine, R., \& Bilmes, J. (1990). Following instructions. In M. Lynch \& S. Woolgar (Eds.), Representation in scientific practice (pp. 323-335). Cambridge, MA: MIT Press.

Barab, S. A., \& Plucker, J. A. (2002). Smart people or smart contexts? Cognition, ability, and talent development in an age of situated approaches to knowing and learning. Educational Psychologist, 37, 165-182. doi:10.1207/S15326985EP3703_3

Bourdieu, P. (1980). Le sens pratique [Logic of practice]. Paris, France: Les Éditions de Minuit.

Bourdieu, P (1992). The practice of refl exive sociology (The Paris workshop). In P. Bourdieu \& L.J.D. Wacquant, An invitation to reflexive sociology (pp. 216-260). Chicago, IL: University of Chicago Press.

Bourdieu, P. (1997). Méditations pascaliennes [Pascalian meditations]. Paris, France: Seuil.

Cacciatore, K. L. (2011). An urgent call for academic chemists to engage in precollege science education. Journal of Chemical Education, 88, 248-250. doi: 10.1021/ed200008q

Case, J., \& Jawitz, J. (2004). Using situated cognition research in researching student experience of the workplace. Journal of Research in Science Teaching, 41, 415-431. doi: 10.1002/tea.20013

Davidson, D. (1986). 1986). A nice derangement of epitaphs. In E. Lepore (Ed.), Truth and interpretation (pp. 433-446). Oxford, UK: Blackwell Publishers.

Durkheim, E. (1919). Les règles de la méthode sociologique [Rules of sociological method]. Paris, France: Felix Alcan.

Foucault, M. (1975). Surveiller et punir: Naissance de la prison [Discipline and punish: Birth of the prison]. Paris, France: Gallimard.

Engeström, Y. (1987). Learning by expanding: An activity-theoretical approach to developmental research. Helsinki, Finland: Orienta-Konsultit.

Garfinkel, H. (1967). Studies in ethnomethodology. Englewood Cliffs, NJ: Prentice Hall.

Garfinkel, H. (2002). Ethnomethodology's program: Working out Durkheim's aphorism. Lanham, MD: Rowman \& Littlefield.

Garfinkel, H. (2007). Lebenswelt origins of the sciences: Working out Durkheim's aphorison. Book two: Workplace and documentary diversity of ethnomethodological studies of work and sciences by ethnomethodology's authors: What did we do? What did we learn? Human Studies, 30, 9-56. doi: 10.1007/s10746-007-9046-9

Garfinkel, H., \& Sacks, H. (1986). On formal structures of practical actions. In H. Garfinkel (Ed.), Ethnomethodological studies of work (pp. 160-93). London, England: Routledge.

Gess-Newsome, J. (2002). The use and impact of explicit instruction about the nature of science and science inquiry in an elementary science methods course. Science \& Education, 11, 5567. doi: $10.1023 / \mathrm{A}: 1013054823482$

Goodwin, C. (1986). Gestures as a resource for the organization of mutual orientation. Semiotica, 62, 29-49. doi: 10.1515/semi.1986.62.1-2.29

Goodwin, C. (2003a). Pointing as situated practice. In S. Kita (Ed), Pointing: Where culture and cognition meet (pp. 217-41). Mahwah, NJ: Lawrence Erlbaum Associates.

Goodwin, C. (2003b). The semiotic body in its environment. In J. Coupland \& R. Gwyn (Eds.), Discourses of the body (pp. 19-42). New York, NY: Palgrave/Macmillan.

Jordan, B., \& Henderson, A. (1995). Interaction analysis: Foundations and practice. Journal of the Learning Sciences, 4, 39-103. doi: 10.1207/s15327809j1s0401_2

Heidegger, M. (1977). Sein und Zeit [Being and time]. Tübingen, Germany: Max Niemeyer. (First published in 1927) 
Henriqson, E., van Winsen, R., Saurin, T. A., \& Dekker, S. W. A. (2011). How a cockpit calculates its speeds and why errors while doing this are so hard to detect. Cognition, Technology, \& Work, 13, 217-231. 10.1007/s10111-010-0161-4

Hindmarsh, J., \& Heath, C. (2000). Embodied reference: A study of deixis in workplace interaction. Journal of Pragmatics, 32, 1855-1878. doi: 10.1016/S0378-2166(99)00122-8

Hofstein, A., \& Lunetta, V. N. (2004). The laboratory in science education: Foundations for the twenty-first century. Science Education, 88, 28-54. doi: 10.1002/sce.10106

Hofstein, A., \& Mamlok-Naaman, R. (2007). Laboratory in science education: The state of the art. Chemistry Education Research and Practice, 8, 105-107. doi: 10.1039/B7RP90003A

Hutchins, E. (1995a). Cognition in the wild. Cambridge, MA: MIT Press.

Hutchins, E. (1995b). How a cockpit remembers its speeds. Cognitive Science, 19, 265-288. doi: $10.1207 / \mathrm{s} 15516709 \operatorname{cog} 1903 \_1$

Joint Information Systems Committee (2006). Designing spaces for effective learning. A guide to 21 st century learning space design. Retrieved Jan 01, 2010, from http://www.jisc.ac.uk/media/documents/publications/learningspaces.pdf

Lave, J. (1988). Cognition in practice: Mind, mathematics, and culture in everyday life. Cambridge, UK: Cambridge University Press.

Lave, J. (1993). The practice of learning. In S. Chaiklin \& J. Lave (Eds.), Understanding practice: Perspectives on activity and context (pp. 3-32). Cambridge, UK: Cambridge University Press.

Lave, J., Murtaugh, M., \& Rocha, O. de la. (1984). The dialectic of arithmetic in grocery shopping. In B. Rogoff \& J. Lave (Eds.), Everyday cognition: Development in social context (pp. 67-94). Cambridge, MA: Harvard University Press.

Lynch, M., Livingston, E., \& Garfinkel, H. (1983). Temporal order in laboratory work. In K. D. Knorr-Cetina \& M. Mulkay (Eds.), Science observed: Perspectives on the social study of science (pp. 205-238). London, UK: Sage.

Marx, K./Engels, F. (1958). Werke Band 3 [Works vol. 3] Berlin, Germany: Dietz.

McDermott, R. P., Gospodinoff, K., \& Aron, J. (1978). Criteria for an ethnographically adequate description of concerted activities and their contexts. Semiotica, 24, 245-275. doi: 10.1515/semi.1978.24.3-4.245

Moje, E. B., Ciechanowski, K. M., Kramer, K., Ellis, L, Carrillo, R., \& Collazo, T. (299==004). Working toward third space in content area literacy: An examination of everyday funds of knowledge and Discourse. Reading Research Quarterly, 39, 38-70. doi: 10.1598/RRQ.39.1.4

Norman, D. A. (1991). Cognitive artifacts. In J. M. Carroll (Ed.), Designing interaction: Psychology at the human-computer interface (pp. 17-38). Cambridge, UK: Cambridge University Press.

National Science Teacher Association (NSTA). (2007). The integral role of laboratory investigations in science instruction. Accessed February 13, 2013 at www.nsta.org/about/positions/laboratory.aspx

Rorty, R. (1989). Contingency, irony, solidarity. Cambridge, UK: Cambridge University Press.

Roth, W.-M. (1995a). Authentic school science: Knowing and learning in open-inquiry science laboratories. Dordrecht, The Netherlands: Kluwer Academic Publishers.

Roth, W.-M. (1995). Inventors, copycats, and everyone else: The emergence of shared (arti)facts and concepts as defining aspects of classroom communities. Science Education, 79, 475-502. doi: $10.1002 /$ sce. 3730790502

Roth, W.-M. (1996). Knowledge diffusion* in a grade 4-5 classroom during a unit on civil engineering: An analysis of a classroom community in terms of its changing resources and 
practices. Cognition and Instruction, 14, 179-220. doi: 10.1207/s1532690xci1402_2

Roth, W.-M. (2008). The nature of scientific conceptions: A discursive psychological perspective. Educational Research Review, 3, 30-50. doi: 10.1016/j.edurev.2007.10.002

Roth, W.-M. (2010). Language, learning, context: Talking the talk. London, UK: Routledge.

Roth, W.-M., \& Barton, A. C. (2004). Rethinking scientific literacy. New York, NY: Routledge.

Roth, W.-M., \& Bowen, G. M. (2001). Of disciplined minds and disciplined bodies. Qualitative Sociology, 24, 459-481. doi: 10.1023/A:1012241029874

Roth, W.-M., \& Lee, Y. J. (2006). Contradictions in theorizing and implementing "communities." Educational Research Review, 1, 27-40. doi: 10.1016/j.edurev.2006.01.002

Roth, W.-M., \& McGinn, M. K. (1998). >undelete science education: /lives/work/voices. Journal of Research in Science Teaching, 35, 399-421. doi: 10.1002/(SICI)10982736(199804)35:4<399::AID-TEA10>3.0.CO;2-5

Roth, W.-M., McGinn, M. K., Woszczyna, C., \& Boutonné, S. (1999). Differential participation during science conversations: The interaction of focal artifacts, social configuration, and physical arrangements. Journal of the Learning Sciences, 8, 293-347. doi: 10.1080/10508406.1999.9672073, 10.1207/s15327809jls0803\&4_1

Roth, W.-M., \& Roychoudhury, A. (1992). The social construction of scientific concepts or The concept map as conscription device and tool for social thinking in high school science. Science Education, 76, 531-557. doi: 10.1002/sce.3730760507

Roth, W.-M., Tobin, K., Carambo, C., \& Dalland, C. (2005). Coordination in coteaching: Producing alignment in real time. Science Education, 89, 675-702. doi: 10.1002/sce.20055

Roth, W.-M., Woszczyna, C., \& Smith, G. (1996). Affordances and constraints of computers in science education. Journal of Research in Science Teaching, 33, 995-1017. doi: 10.1002/(SICI)1098-2736(199611)33:9<995::AID-TEA3>3.0.CO;2-Q

Scribner, S. (1984). Studying working intelligence. In B. Rogoff and J. Lave (Eds.), Everyday cognition: Its development in social context (pp. 9-40). Cambridge, MA: Harvard University Press.

Schwartz, R. S., Lederman, N., \& Crawford, B. A. (2004). Developing views of nature of science in an authentic context: An explicit approach to bridging the gap between nature of science and scientific inquiry. Science Education, 88, 610-645. doi: 10.1002/sce.10128

Suchman, L. (1987). Plans and situated actions: The problem of human-machine communication. Cambridge, UK: Cambridge University Press.

Tobin, K. G. (1987). The role of wait time in higher cognitive level learning. Review of Educational Research, 57, 69-95. doi: 10.2307/1170357, 10.3102/00346543057001069

Vygotsky, L. S. (1989). Concrete human psychology. Soviet Psychology, 27(2), 53-77. doi: 10.2753/RPO1061-0405270253

Wacquant, L. (2004). Body \& soul: Notebooks of an apprentice boxer. Oxford, UK: Oxford University Press. 
Appendix: Transcription conventions

\begin{tabular}{|c|c|}
\hline Symbol & Use \\
\hline [text] & Brackets indicate the start and end points of overlapping speech \\
\hline$; \cdot, ?$ & $\begin{array}{l}\text { Punctuation marks of semicolon, period, comma and question mark indicate } \\
\text { movement of pitch toward the end of utterance segment (tendency): "down," } \\
\text { "strongly down," "up," and "strongly up" }\end{array}$ \\
\hline$\uparrow \downarrow$ & $\begin{array}{l}\text { Arrows indicate movement of pitch: upward and downward jump between } \\
\text { phonemes }\end{array}$ \\
\hline$\cdots$ & $\begin{array}{l}\text { Diacritics indicate movement of pitch: "upward," "downward," "upward and } \\
\text { then downward," "downward and then upward" contour of phonemes that } \\
\text { follow }\end{array}$ \\
\hline$=$ & Indicates the break and subsequent continuation of a single utterance \\
\hline$()$. & Period inside single parentheses a brief pause, usually less than 0.2 seconds. \\
\hline$(3.21)$ & A number in parentheses indicates the time, in seconds, of a pause in speech \\
\hline ALL CAPS & Capitalized text indicates shouted or increased volume speech \\
\hline underline & Underlined text indicates the speaker is emphasizing or stressing the speech \\
\hline$<<a l l>$ text $>$ & $\begin{array}{l}\text { Indicates that the enclosed speech was delivered more rapidly than usual for } \\
\text { the speaker }\end{array}$ \\
\hline$<<$ len $>$ test $>$ & $\begin{array}{l}\text { Lento indicates that the enclosed speech was delivered more slowly than usual } \\
\text { for the speaker }\end{array}$ \\
\hline$:::$ & Indicates prolongation of a sound, each colon corresponding to 0.1 seconds \\
\hline hhh & Audible exhalation, each " $\mathrm{h}$ " corresponding to 0.1 seconds \\
\hline$((t e x t))$ & Text in double parentheses indicates annotation of non-verbal activity \\
\hline ( ???) & Question marks in parentheses indicates unclear sound \\
\hline haha hehe hihi & Laughter \\
\hline
\end{tabular}

\section{Bio}

Wolff-Michael Roth is Lansdowne Professor of applied cognitive science at the University of Victoria. His research concerns the learning of science and mathematics across the life span. His most recent works include First-Person Method: For a Rigorous Approach to the Study of Living / Lived Experience (Sense Publishers, 2012). Passibility: At the Limits of the Constructivist Metaphor (Springer, 2011), Geometry as Objective Science in Elementary Classrooms: Mathematics in the Flesh (Routledge, 2011), and, with L. Radford, A Cultural-historical Perspective on Mathematics Teaching and Learning (Sense Publishers, 2011).

Pei-Ling Hsu is assistant professor of teacher education at the University of Texas at El Paso, Texas, USA. Her research interests focus on partnership with scientists, discourse studies, students' career pursuits in science, and preservice teachers' identity development. She is the coauthor of two books-Analyzing Communication: Praxis of Method and Authentic Science Revisited: In Praise of Diversity, Heterogeneity, Hybridity. Her recent publications appear in the Cultural Studies of Science Education, Journal of Research in Science Teaching, Science Education, Research in Science Education, and International Journal of Science Education. 
Figure 1

Click here to download Colour Figure: F01.doc
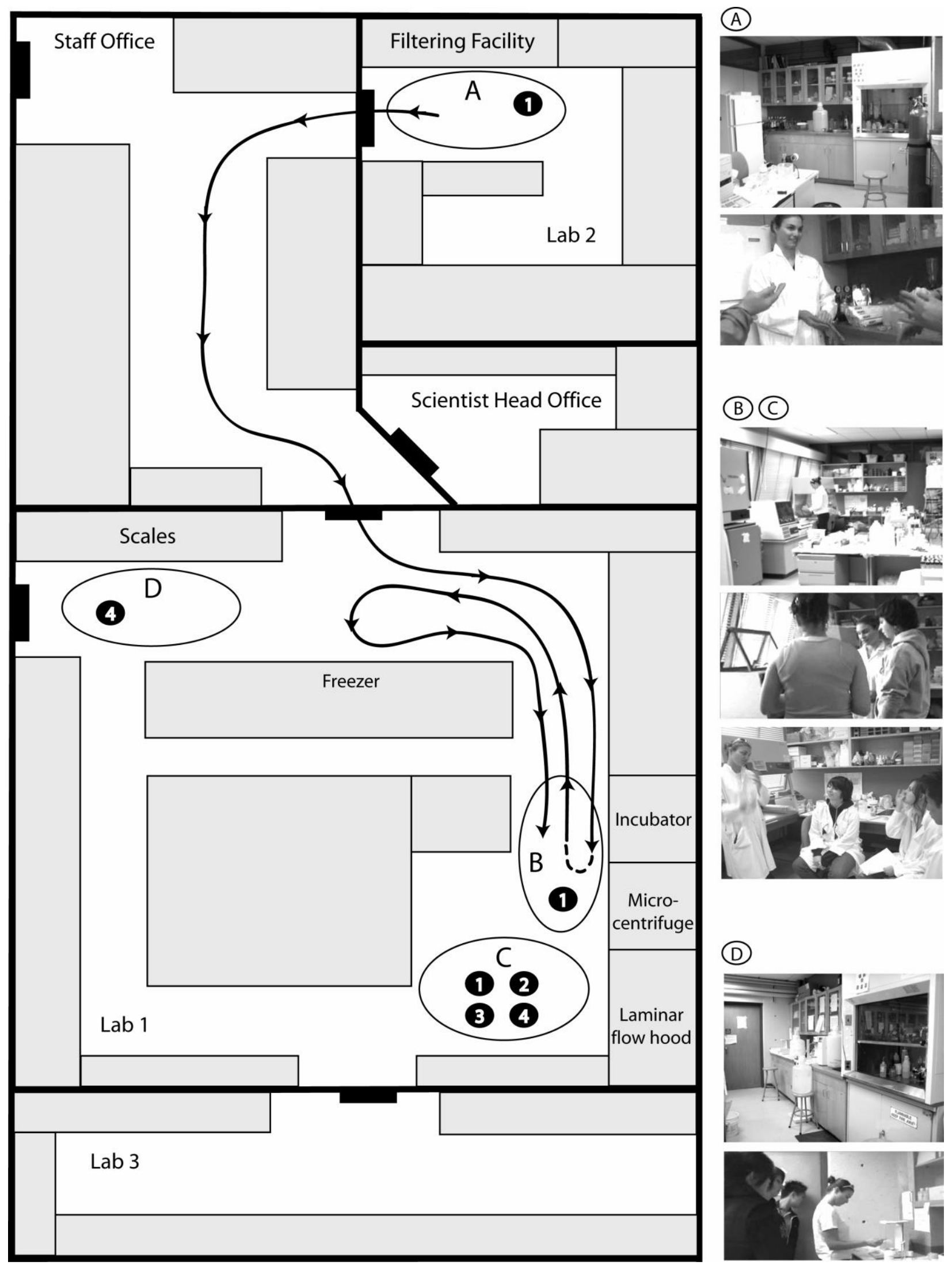

(B) (C)

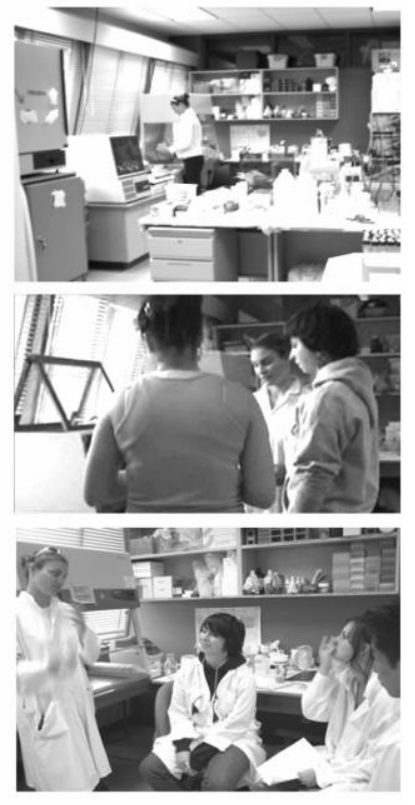

(D)

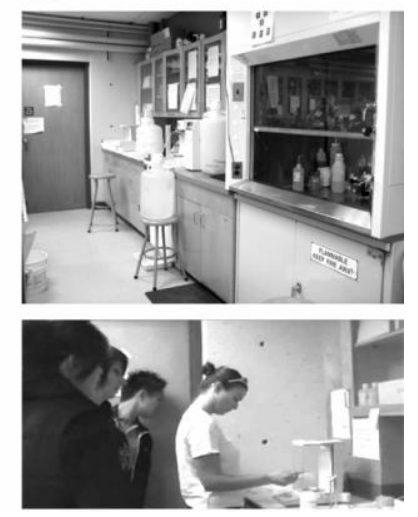


Fig. 1. A layout of the laboratory, four pedagogical spaces (A, B, C, and D) and the discourse trajectory (Episode 2) of introducing Petri dishes' bacteria colonies on the first day of the lab internship. The laboratory includes five rooms (i.e., Staff office, Scientist head office, Lab 1, Lab 2, and Lab 3). Students resided in Space A and B on the first day, Space C for the entire lab internship (i.e., four days) and Space D on the forth day of their lab internship. (Black squares indicate the location of doors; gray squares indicate the location of furniture or equipment; black circle with white number 1-4 indicate the four days of the lab internship). 

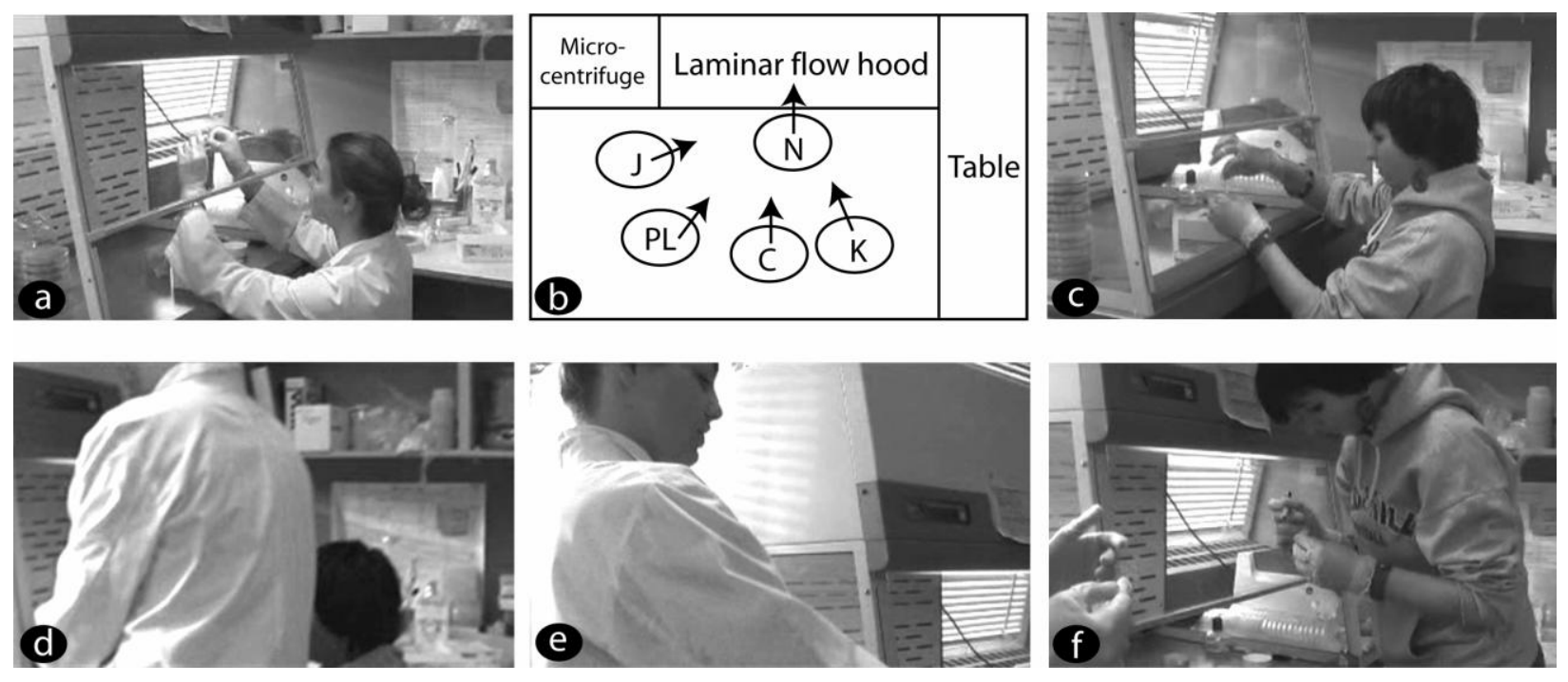

Fig. 2. (a) Nora squats down to practice a technique (nurturing bacteria) in front of the laminar flow hood; (b) the spatial relationship when Nora $(\mathrm{N})$ practices the technique; (c) Cindy squats down to practice the technique (Nora stands on Cindy's left side and other people stand behind Cindy); (d) To answer Kelly's question, Nora turns over to demonstrate the "right" position for working with the laminar flow hood; (e) Nora gazes toward and her right hand points to Cindy who squats at Nora's left side; (f) Cindy stands up after Nora articulates the fact that the "right" position for doing work with the laminar flow hood is standing up rather than squatting down like Cindy. 
Click here to download Colour Figure: F03.doc
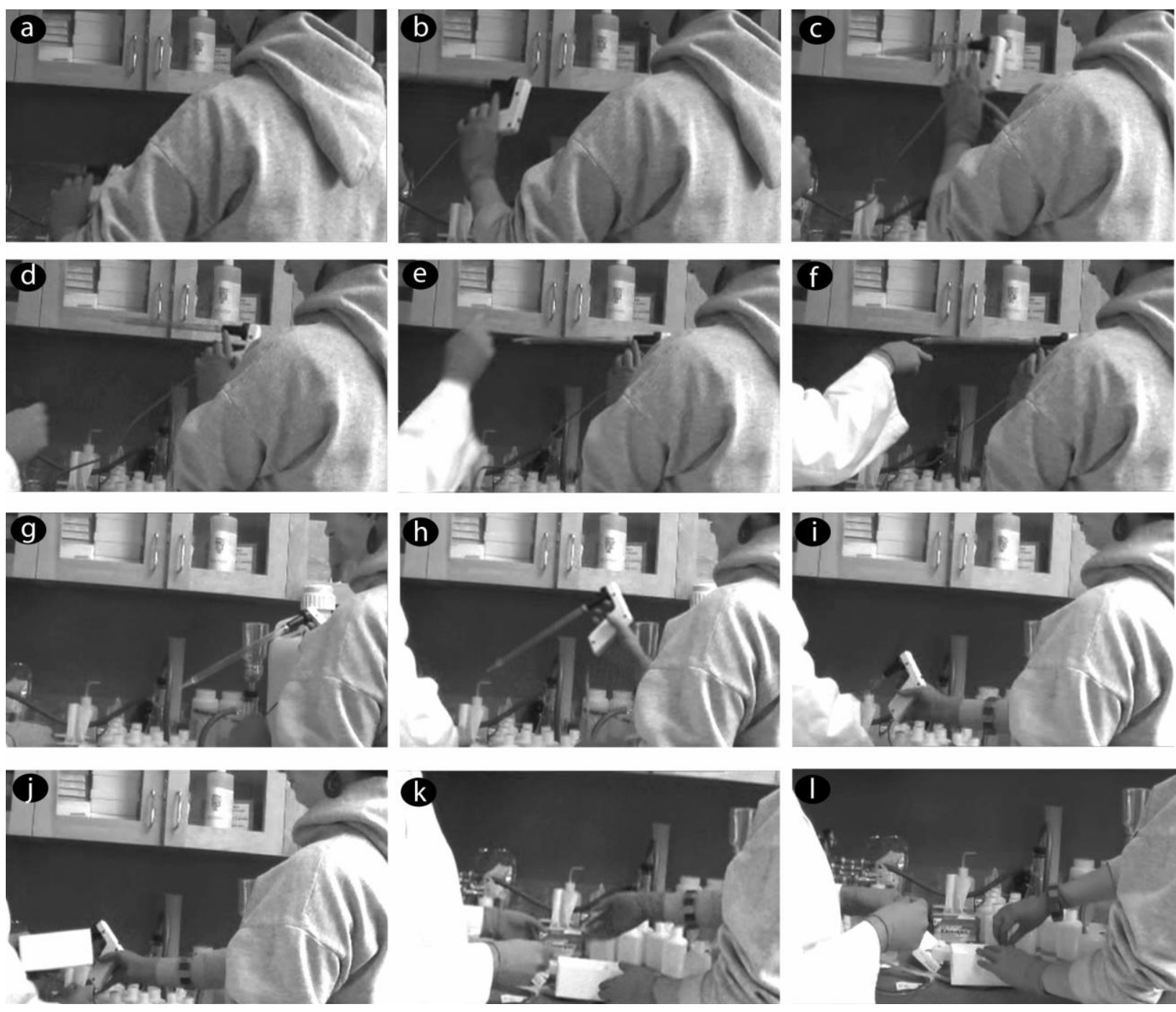

bench

box of

filter paper

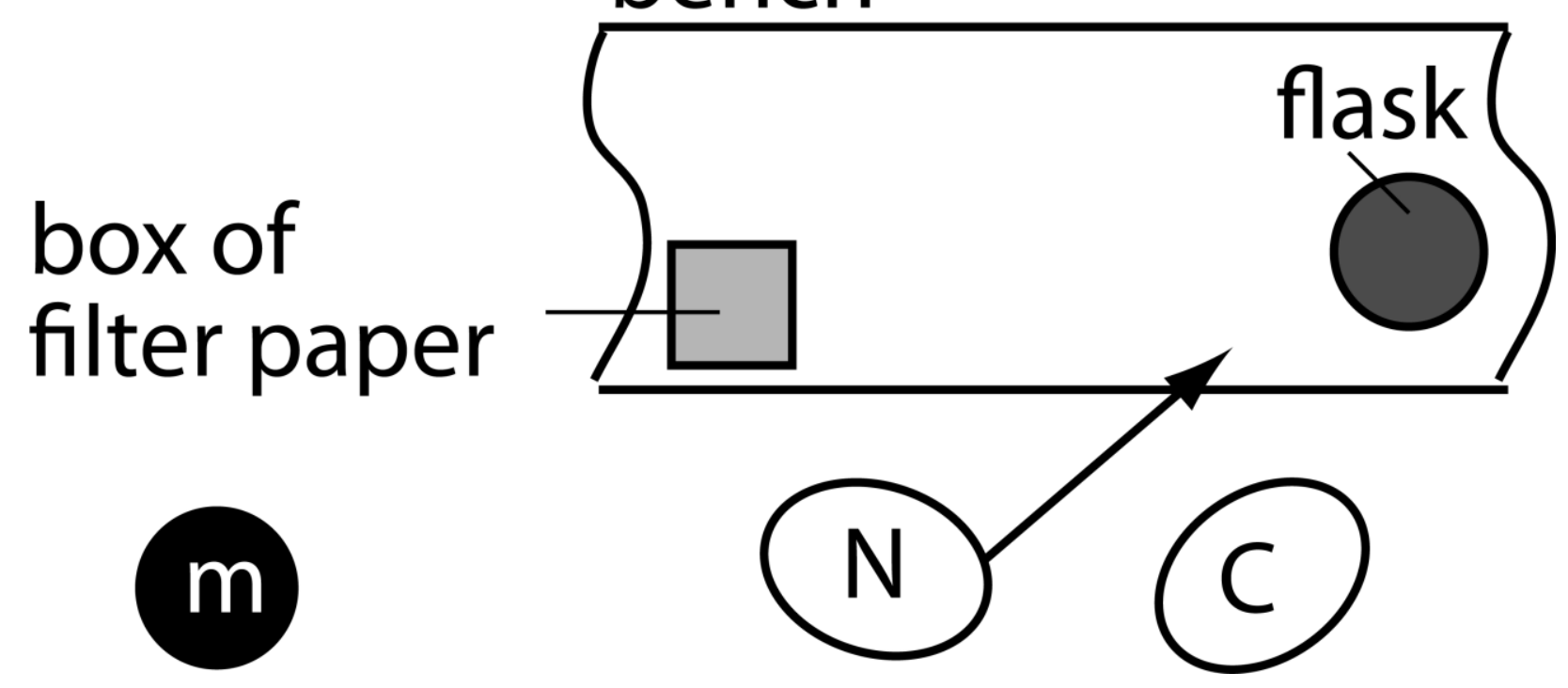

m 
Fig. 3. (a, b, c) Cindy picks up the wrong tool (i.e., pipette) that is spatially closer to her. (d, e, f) Nora points out a space (i.e., the location of the pump filter) where Cindy needs to work on first. $(g, h, i)$ Cindy then returns and puts away the pipette. $(j, k, 1)$ Nora picks up the right tool (i.e., paper filter package box) and puts it closer to Cindy. Spatial configuration of participants and materials (m). 

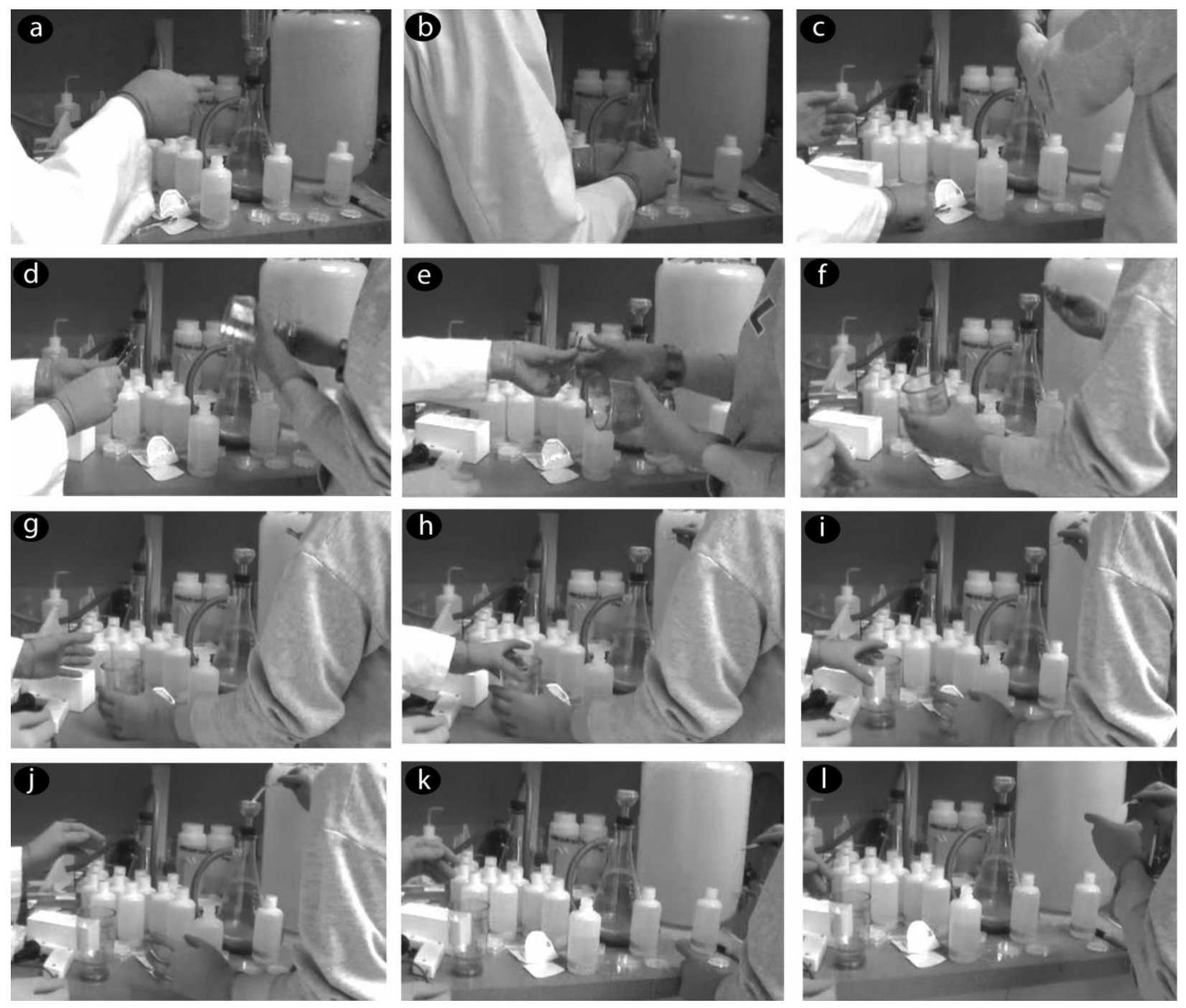

Fig. 4. (a, b) Nora points to the pump filter direction and opens the cover of the second

Petri dish. (c) Cindy then uses her left hand to pick up the pump filter cover while Nora uses her right hand to pick up the tweezers. (d) Cindy turns back to Nora who switches the tweezers from her right hand to her left hand. (e) Nora then passes the tweezers to Cindy's right hand. (f, g) Cindy's right hand then orients toward the pump filter while her left hand is putting down the pump filter cover on the table. (h, i) Nora then receives the cover filter and puts it away from Cindy. (j, k, l) Cindy then uses the tweezers to pick up the paper filter and puts it into the second Petri dish. 


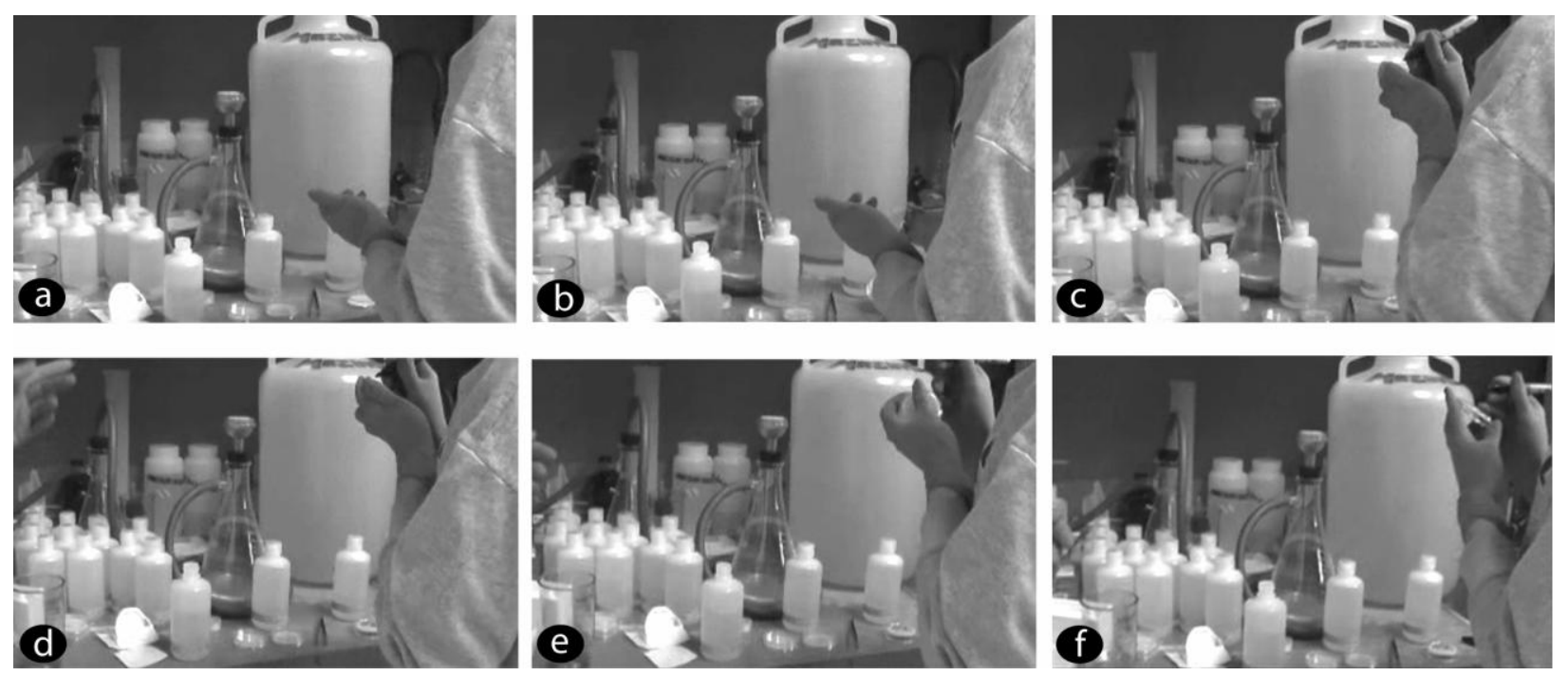

Fig. 5. (a, b, c) Cindy turns over Nora's Petri dish to check how Nora labels her Petri dish. (d) Cindy then orients her pen to label on the front side of her Petri dish and gets a response from Nora saying that the right place to label is on the backside of the Petri dish. $(e, f)$ Cindy turns over her Petri dish and labels source information on the backside of the Petri dish. 

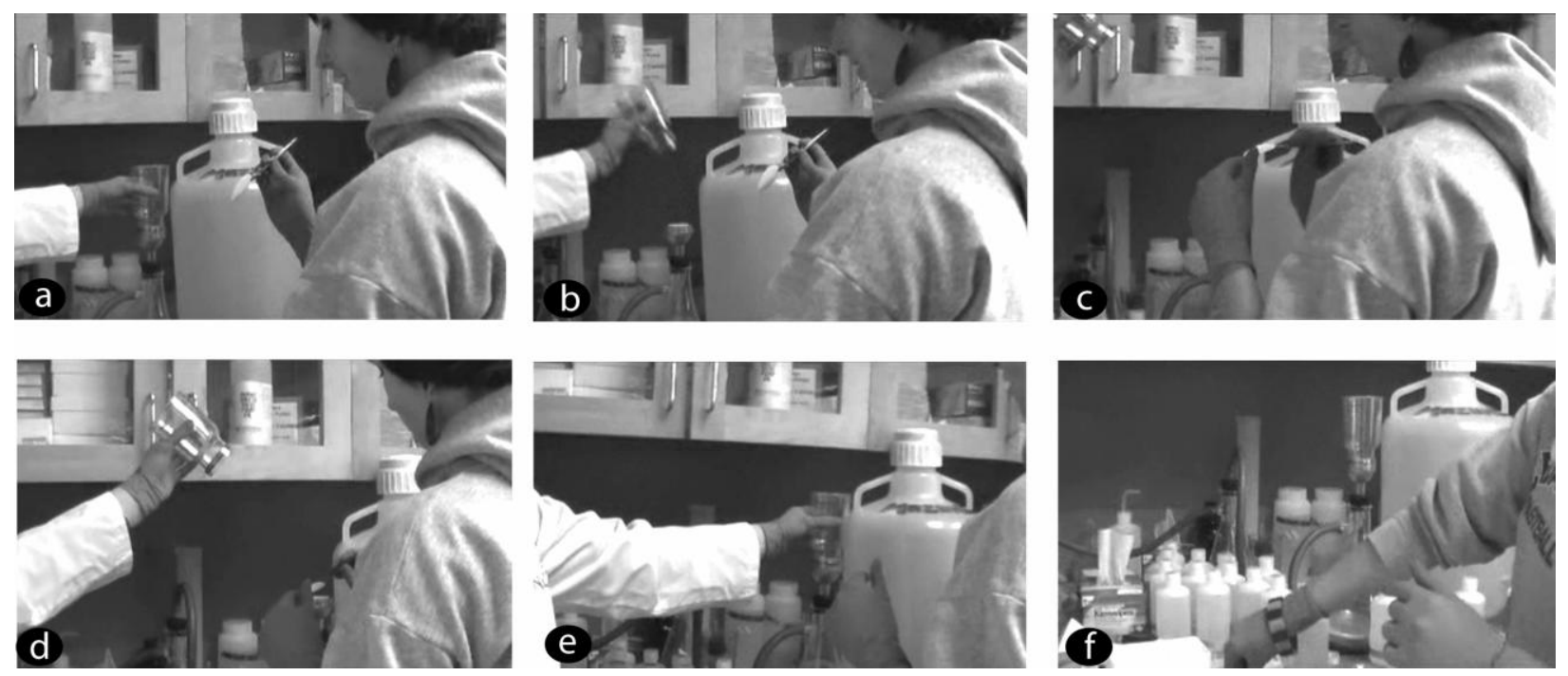

Fig. 6 (a, b) When Cindy successfully pulls out the paper filter, Nora's body and her left hand orient to pick up the pump filter cover. (c) Cindy points to the paper filter and make sure which side goes up. (d) Cindy puts the paper filter on the flask and Nora descends her hand with the cover. (e) Nora puts the cover back on the flask. (f) Cindy puts down the tweezers on the table. 


\section{Bio}

Wolff-Michael Roth is Lansdowne Professor of applied cognitive science at the University of Victoria. His research concerns the learning of science and mathematics across the life span. His most recent works include First-Person Method: For a Rigorous Approach to the Study of Living / Lived Experience (Sense Publishers, 2012). Passibility: At the limits of the constructivist metaphor (Springer, 2011), Geometry as objective science in elementary classrooms: Mathematics in the flesh (Routledge, 2011), and, with L. Radford, A cultural-historical perspective on mathematics teaching and learning (Sense Publishers, 2011).

Pei-Ling Hsu is assistant professor of teacher education at the University of Texas at El Paso, Texas, USA. Her research interests focus on partnership with scientists, discourse studies, students' career pursuits in science, and preservice teachers' identity development. She is the co-author of two books-Analyzing communication: Praxis of method and Authentic science revisited: In praise of diversity, heterogeneity, hybridity. Her recent publications appear in the Cultural Studies of Science Education, Journal of Research in Science Teaching, Science Education, Research in Science Education, and International Journal of Science Education. 